DOE Report No. DOE/PC/89781-8

Title:

\title{
A NOVEL COAL FEEDER FOR PRODUCTION OF LOW SULFUR FUEL
}

\author{
S. J. Khang and L. Lin \\ Chemical Engineering Department \\ T. C. Keener, P. Yeh \\ Civil and Environmental Engineering Department \\ University of Cincinnati \\ Cincinnati, OH 45221
}

\begin{abstract}
A dual-screw feeder was designed for desulfurization of coal. This reactor contains two screv' tubes, the inner tube acting as a coal pyrolizer and the outer tube acting as a desulfurizer with hot calcined lime pellets or other renewable sorbent pellets. The objective of this project is to study the feasibility of an advanced concept of desulfurization and possibly some denitrification in this coal feeder.

In this year, two basic studies have been performed: 1) the desulfurization and 2) the denitrification due to mild pyrolysis. Specifically, the following tasks have been performed: 1) Setting up the Dual-Screw reactor, 2) Determination of the pyrolysis product and the sulfur distribution in char, tar and gas based on experimental data, 3) Study of the devolatilization, the desulfurization kinetics and the denitrification kinetics and obtaining the basic kinetic parameters, 4) Study of the sulfur removal efficiency of lime pellets fed into the outer tube of the dual-feeder reactor, 5) Study of the effect of the coal particle size on pyrolysis and desulfurization, 6)Study of the coal pyrolysis and desulfurization using a TGA(Thermal Gravimetric Analyzer). Some preliminary conclusions are as follows: 1) Under the present experimental conditions, the devolatilization and the denitrification processes, as well as the desulfurization process, can be simulatei by a first-order reaction model. 2) The desulfurization rate increases quickly with temperature. Up to $20 \%$ of denitrification was achieved. 3) The activation energie's for devolatilization and desulfurization are approximately $14,090 \mathrm{cal} / \mathrm{mol}$ and $5,389 \mathrm{cal} / \mathrm{mol}$ respectively. 4)Between 4-35 mesh, the coal particle size has no effect on both pyrolysis and desulfurization. 5) The $\mathrm{H}_{2} \mathrm{~S}$ concentration in gas after reacted with lime pellets is below the detection limit of our gas chromatograph, which demonstrated the very high sulfur removal efficiency of $\mathrm{CaO}$ pellets in this dual-feeder reactor, 6) The TGA experiment shows that the swelling point of Ohio $\# 8$ coal is about $450^{\circ} \mathrm{C}$ and most of the removable sulfur releases at this temperature.
\end{abstract}

The first section of this report describes the results of desulfurization efforts. The second section summarizes the denitrification results.

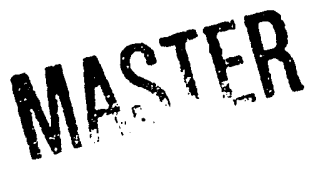

DISTRIBUTION OF THIS DOCUMENT IS UNLIMITED

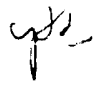




\section{Table of Contens}

\section{SECTION I. DESULFURIZATION}

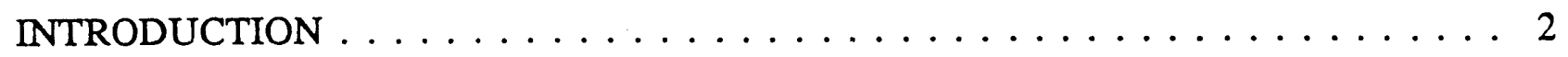

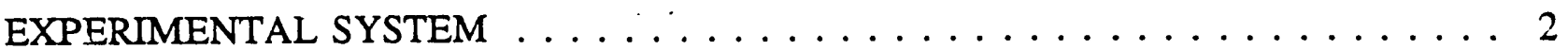

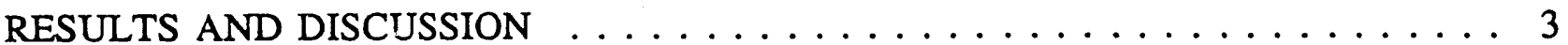

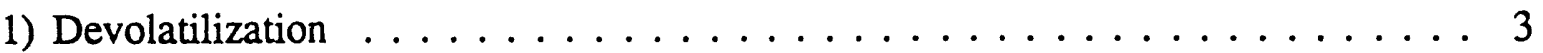

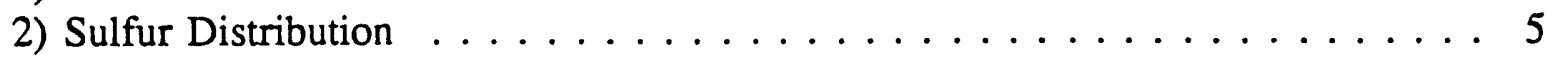

3) Desulfurization Kinetics . . . . . . . . . . . . . . . . . 5

4) The Sulfur Removal Efficiency of $\mathrm{CaO}$ in Dual-Screw Feeder . . . . . . . . . . . 6

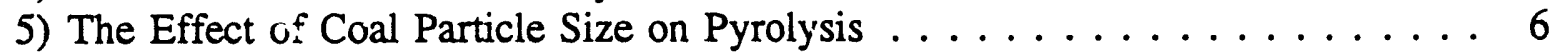

6) The Effect of Coal Particle Size on Desulfurization . . . . . . . . . . . . 6

7) The TGA experimental result .................... 7

PLANNED FUTURE WORK $\ldots \ldots \ldots \ldots \ldots \ldots \ldots \ldots \ldots$

UNEXPECTED PROBLEMS ENCOUNTERED . . . . . . . . . . . . . . 7

\section{SECTION II. DENITRIFICATION}

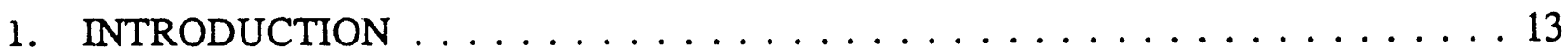

1.1 Formation and Properties of Coal $\ldots \ldots \ldots \ldots \ldots$

1.1 .1 Formation of Coal . . . . . . . . . . . . . . . . 13

1.1.2 Chemical Properties of Coal . . . . . . . . . . . . . . 13

1.2 Emissions of NOx in Coal Combustion . . . . . . . . . . . . . 14

1.3 The Concept of Coal Denitrification . . . . . . . . . . . . 14

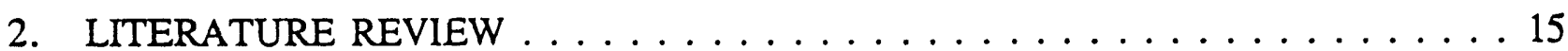

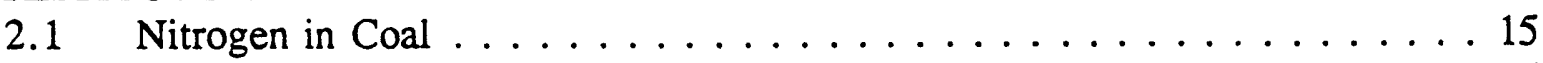

2.1 .1 Nitrogen in Coal Extracts . . . . . . . . . . . . . . 15

2.1.2 Nitrogen in the Product of Coal Depolymerization . . . . . . . . 15

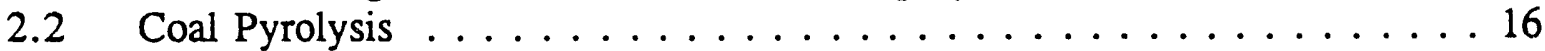

2.2.1 Products of Coal Pyrolysis . . . . . . . . . . . . . 17

2.2.2 Mild Pyrolysis of Coal . . . . . . . . . . . . . . 17

2.3 Modeling of Nitrogen Evolution $\ldots \ldots \ldots \ldots$

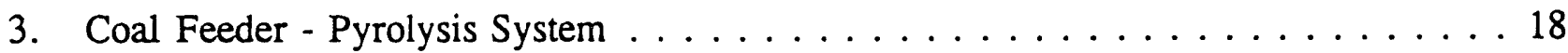

3.1 Initial Scheme of Coal Feeder . . . . . . . . . . . . . . . 19

3.2 Modified Scheme of Coal Feeder . . . . . . . . . . . . . . 20

4. DENITRIFICATION TESTS AND ANALYSIS . . . . . . . . . . . . . 20

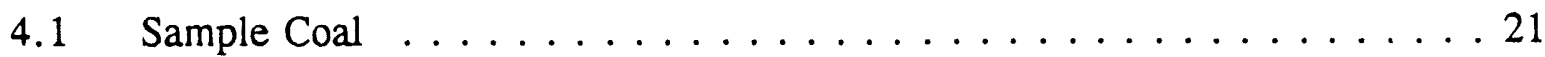

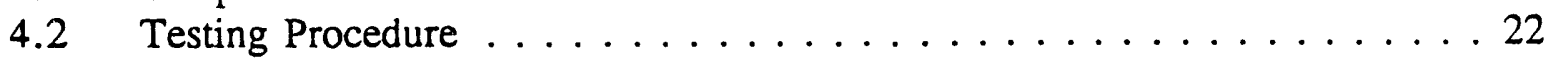




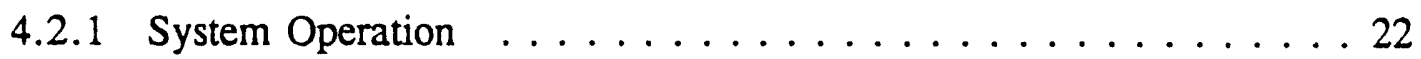

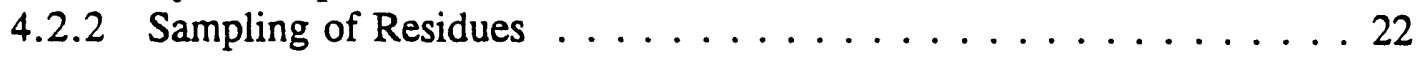

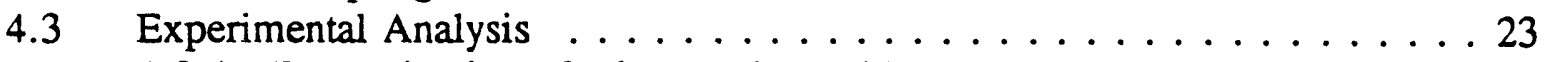

4.3.1 Determination of Nitrogen in Residues . . . . . . . . . 23

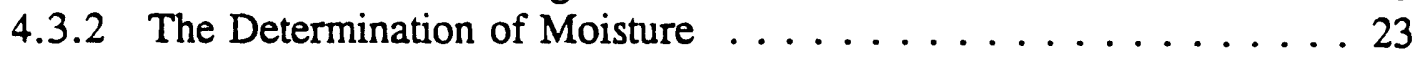

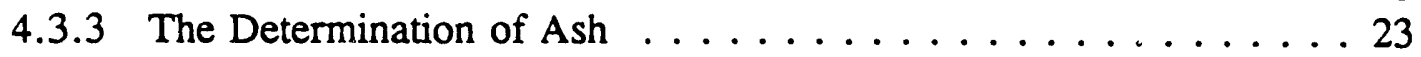

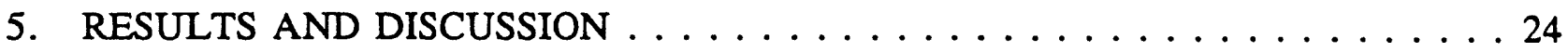

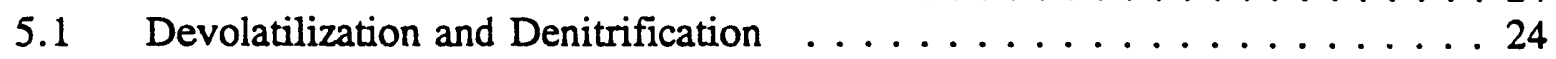

5.2 Ash Tracer as Devolatilization . . . . . . . . . . . . 43

5.3 The Effects of Pyrolysis Temperature . . . . . . . . . . . 43

6. CONCLUSIONS AND RECOMMENDATION $\ldots \ldots \ldots \ldots \ldots \ldots \ldots \ldots$

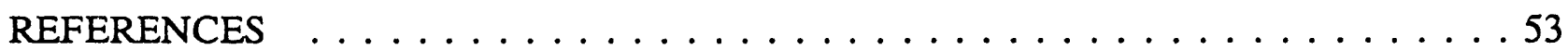




\section{SECTION I. DESULFURIZATION}

\section{INTRODUCTION}

Coal is predominantly used as a fuel for the production of electricity. Air pollution arising from coal combustion is now a major concern as coal is second to the petroleum and nature gas. Various methods of sulfur removal from coal have been developed during the last two decades. However, the cost, as well as the low sorbent utilization, of current desulfurization technologies is still a drawback to the increased use of iigh sulfur coals.

A novel dual-screw feeder reactor was designed, for this project, to remove the sulfur in coal before combustion while the sulfur-compounds are converted to gaseous forms of product, mainly $\mathrm{H}_{2} \mathrm{~S}$, during a mild pyrolysis process and are still highly concentrated. Two basic concepts are involved in the development of this reactor: the mild pyrolysis of coal and the reaction of $\mathrm{H}_{2} \mathrm{~S}$ with calcium based sorbent. It combines the pyrolysis and the sulfur removal processes together.

Under mild reducing pyrolysis condition, some pyritic sulfur in coal is released mainly in the form of $\mathrm{H}_{2} \mathrm{~S}$. The release mechanism of organic sulfur is not well investigated, however it is generally known that the majority of organic sulfur is released in the form of $\mathrm{H}_{2} \mathrm{~S}$ and COS below $600^{\circ} \mathrm{C}$. The formation of $\mathrm{H}_{2} \mathrm{~S}$ is the key point to the enhancement of sorbent utilization in this project. The reaction rate of $\mathrm{H}_{2} \mathrm{~S}$ is significantly higher than that of $\mathrm{SO}_{2}$ with $\mathrm{CaO}$ at the same temperature. Furthermore, the smaller molar volume of $\mathrm{CaS}$ than that of $\mathrm{CaSO}_{4}$ indicates that the formation of $\mathrm{CaS}$ could proceed more completely than that of $\mathrm{CaSO}_{4}$. Therefore, the higher utilization of sorbent $(\mathrm{CaO})$ is possible.

In the pyrolysis process, coal is converted into char, tar and noncondensable gas. Different pyrolysis conditions may result in different product distribution and different sulfur distribution. Generally, the gaseous compounds include $\mathrm{CO}, \mathrm{CO}_{2}, \mathrm{H}_{2}$, hydrocarbon and nitrogen and sulfur containing species. Coal pyrolysis is a very coniplicated process. The result strongly depends on the experimental conditions including the type of reactor used, the range of temperature, the heating rate and the method of analysis of the products.

Much attention has been paid to the study of coal pyrolysis process. The experimental methods generally include fluidized bed, fixed bed and batch reactors. No information is available on a dual-screw feeder reactor in which coal pyrolysis and sulfur removal take place simultaneously. The complex decomposition phenomena of coal in pyrolysis process is not yet well known. In study of coal pyrolysis kinetics, the over-all reaction rate is frequently used.

\section{EXPERIMENTAL SYSTEM}

The experimental system consists of three units. 1) The screw feeder reactor, 2) Sampling unit and 3) The analysis unit.

The screw feeder reactor consists mainly of two augers which are driven by two motors separately. The inner screw is used for coal pyrolysis, and the outer one is for sulfur removal with calcined limestone pellets or other renewable sorbent pellets. By adjusting the speed of the motors, the particle residence time can be easily controlled. The reaction system is well sealed. In considering the high corrosiveness of $\mathrm{H}_{2} \mathrm{~S}$ and other evolved gases, all parts of this reactor 
are made of stainless steel. Two quenching tanks are used to collect char products and reacted sorbent pellets.

Three sections of band type electrical heaters with three separate temperature controllers were installed on the surface of outer tube to provide uniform temperature distribution along the feeder tube. Several thermocouples are employed to measure the surface temperature.

After pyrolysis, the volatiles flow out of the reactor and flow through the condensers. The condensable substances ("tar", it is actually a mixture of tar and water) are condensed there and the cooled gas entrains the gas collection unit. To determine the gas composition, a Perkin Elmer Gas Chromatography (GC) is used. Two GC columns were installed in this unit. One is for $\mathrm{H}_{2} \mathrm{~S}$, and the other for hydrocarbon, carbon oxides, hydrogen and nitrogen. The GC operating temperature was experimentally selected at $70^{\circ} \mathrm{C}$. Helium is used as the carrier gas. All standard curves were determined prior to experiments. A sample bag is used to collect the cooled gas.

At the end of experiment, the weight and the volume of the collected noncondensable gas are measured. The amount of char and tar are determined gravimetrically and the mass balance is made.

The relation between residence time and screw rotation speed was determined by using the metal balls.

In the TGA experiment, the heating rate was set as $50^{\circ} \mathrm{C} / \mathrm{min}$ and the isothermal temperature was $500^{\circ} \mathrm{C}$. A H $\mathrm{H}_{2} \mathrm{~S}$ Analyzer was connected to the outlet of the TGA to measure the $\mathrm{H}_{2} \mathrm{~S}$ on-line. The flow rate of the carrier gas $\left(\mathrm{N}_{2}\right)$ was $160 \mathrm{ml} / \mathrm{min}$.

The sulfur content in char and coal is analyzed by using a LECO sulfur analyzer.

The Ohio \#8 coal (4-35 mesh) was used in the experiments. The total sulfur content in coal sample is $3.15 \%$ (wt).

\section{RESULTS AND DISCUSSION}

\section{1) Devolatilization}

The measured product distribution data are listed in Table 1. As the temperature rises, the yields of both tar and gas increase. The devolatilization yield data are plotted in Fig. 1.
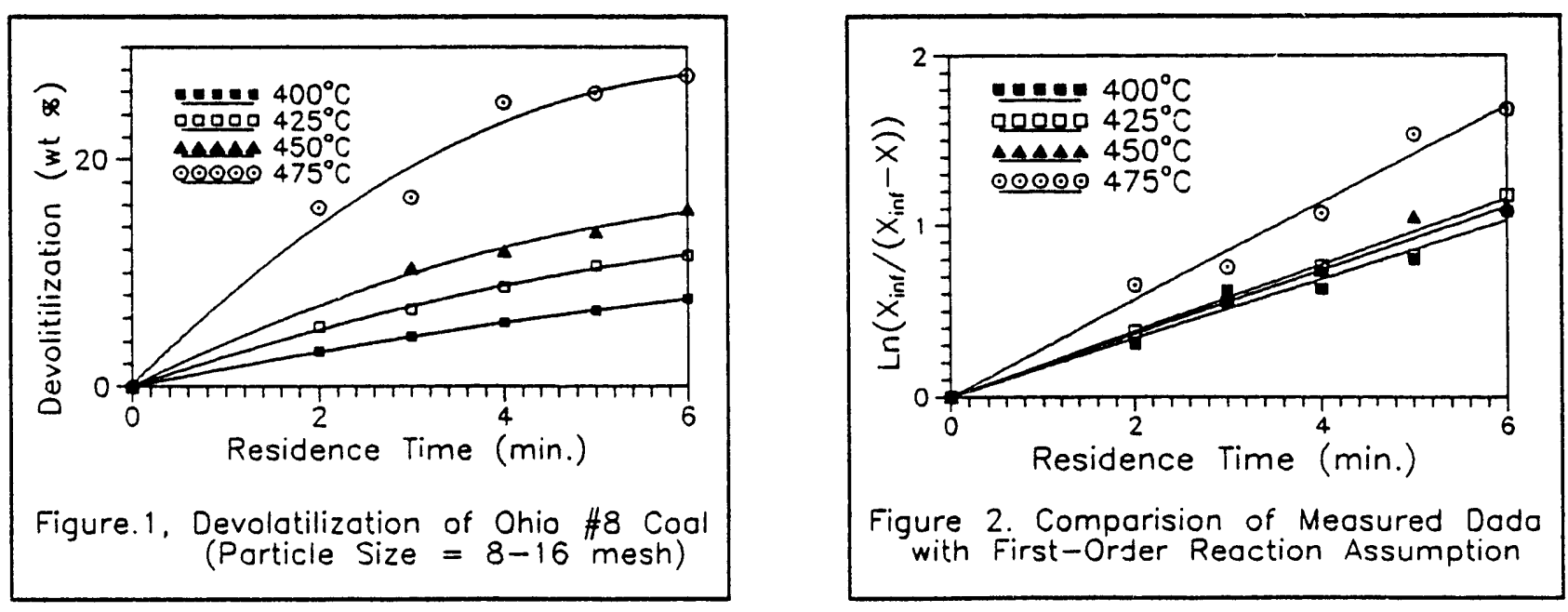
By assuming first-order reaction:

$$
\frac{d(W-W)}{d t}=-k_{v}(W-W)
$$

we have

$$
\frac{x_{\infty}-x}{x_{\infty}}=\exp \left(-k_{v} t\right)
$$

where $\quad \mathrm{W}=$ The weight of coal at time $\mathrm{t}$

$\mathrm{W}_{\infty}=$ The weight of coal when $\mathrm{t}=\infty$

$\mathrm{x}=\left(\mathrm{W}_{\mathrm{o}}-\mathrm{W}\right) / \mathrm{W}_{\mathrm{o}}$, The conversion

$\mathrm{W}_{\mathrm{o}}=$ The weight of coal at $\mathrm{t}=0$

$\mathrm{x}_{\infty}=\left(\mathrm{W}_{0}-\mathrm{W}_{\infty}\right) / \mathrm{W}_{0}$

Equation (2) can be written as:

$$
\operatorname{Ln}\left(\frac{x_{-}}{x_{-}-x}\right)=k_{v} t
$$

The limiting conversion $x_{\infty}$ represents the effective volatile content of the coal which $d$ ipends on temperature and is different from the volatile matter VM determined by proximate analysis. Theoretically, $x_{\infty}$ could be determined by using infinite residence time. However, because of the difference of outer tube surface temperature and the reactant temperature (in experiment, it is very difficult to measure the actual temperature of the coal particles), $x_{\infty}$ is unavailable from experiment. In practice, both $x_{\infty}$ and $k_{v}$ in Eq.(3) are obtained by linear regression with the initial condition $\mathrm{x}=0$ at $\mathrm{t}=0$. Table 2 shows $\mathrm{x}_{\infty}$ and $\mathrm{k}_{\mathrm{v}}$ values at different temperat res. $\mathrm{A}$ comparison of the experimental data with Equation (3) (Figure 2) indicates a rea ionable agreement between assumption and measurement. The activation energy of devolatilization is $14,090 \mathrm{cal} / \mathrm{mol}$ which was obtained by using the Arrhenius law(Fig.3). Figure $4 \mathrm{sh}$ )ws the
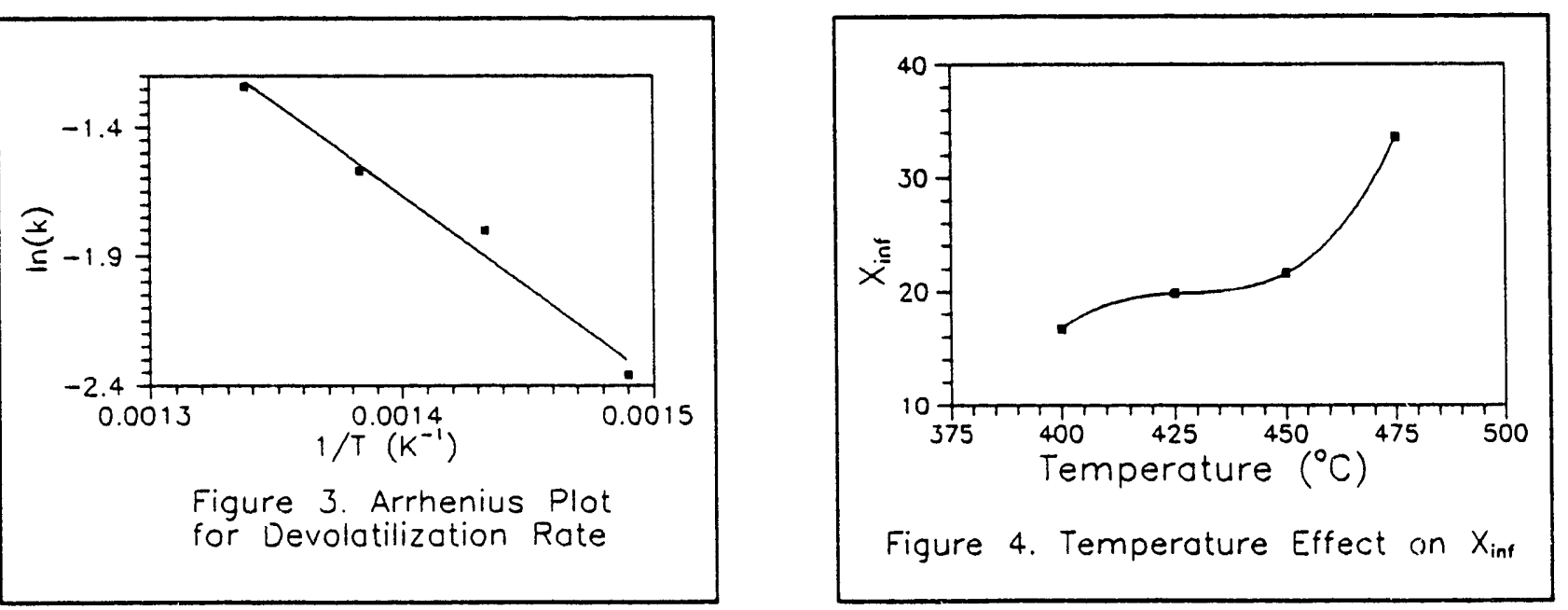
relation between $x_{\infty}$ and temperature.

\section{2) Sulfur Distribution}

The data in Tables 3 and 4 show the sulfur concentration in char and gas products after pyrolysis. It is seen that the sulfur concentration in gas remains almost the same level at certain reaction temperature while the residence time changes. Figure 5 gives the relationship between reaction temperature and sulfur concentration in gas. It is observed that the hydrogen sulfide concentration in gas product tends to reach a upper limit about $4.2 \%$. On the other hand, it is observed the sulfur content in char depends on both reaction temperature and residence time. As temperature and residence time increase, the concentration of sulfur in char decreases. Table 5 presents the result of sulfur distribution in pyrolysis products under different experimental conditions. When reaction temperature and residence time increase, the desulfurization rate increases quickly. At $475^{\circ} \mathrm{C}, 33.2 \%$ of sulfur in coal is removed in a residence time of 6 minutes.

\section{3) Desulfurization Kinetics}

The desulfurization yield data are given in

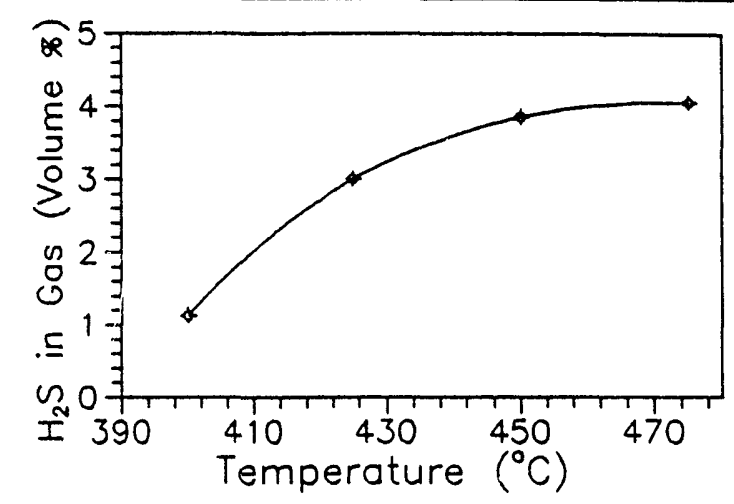

Figure 5. Effetc of Temperature on $\mathrm{H}_{2} \mathrm{~S}$ Concentration in Gas

Table 5 and Figure 6. By assuming the first order reaction of desulfurization as was developed in the study of pyrolysis, we have:

$$
\operatorname{Ln}\left(\frac{s_{\infty}}{s_{\infty}-s}\right)=k_{s} t
$$

$$
\begin{aligned}
& \text { where } s=\left(\mathrm{W}_{s o}-\mathrm{W}_{\mathrm{s}}\right) / \mathrm{W}_{\mathrm{so}} \\
& \qquad \begin{array}{l}
\mathrm{s}_{\infty}=\left(\mathrm{W}_{\mathrm{so}}-\mathrm{W}_{\mathrm{so}}\right) / \mathrm{W}_{\mathrm{so}} \\
\mathrm{W}_{\mathrm{s}}=\text { The weight of sulfur in coal } \\
\mathrm{W}_{s o}=\text { The weight of sulfur in coal at } \mathrm{t}=0 \\
\mathrm{~W}_{s o}=\text { The weight of sulfur in coal when } \mathrm{t}=\text { infinite }
\end{array}
\end{aligned}
$$

The limiting conversion $s_{\infty}$ is a function of temperature. In the complex structure of the coal, sulfur atoms exist in different bonds with other atoms. To break these bonds which have different bond energies, different levels of energy is necessary. $s_{\infty}$ could be regarded as the fraction of total sulfur atoms whose bonds could be broken at a given temperature.

Figure 7 shows a reasonable fit between the experiment data and the first order reaction model. The $s_{\infty}$ and $k_{s}$ values are given in Table 6 . The activation energy of the desulfurization was estimated to be $5,389 \mathrm{cal} / \mathrm{mol}$, by using the Arrhenius rule(Figure 8 ). This value is smaller than the volatilization activation energy, which indicates that the sulfur component is easier to be released than volatiles in coal. It is in agreement with the experimental observation in that, as the temperature rises, the concentration of sulfur in char is reduced. 


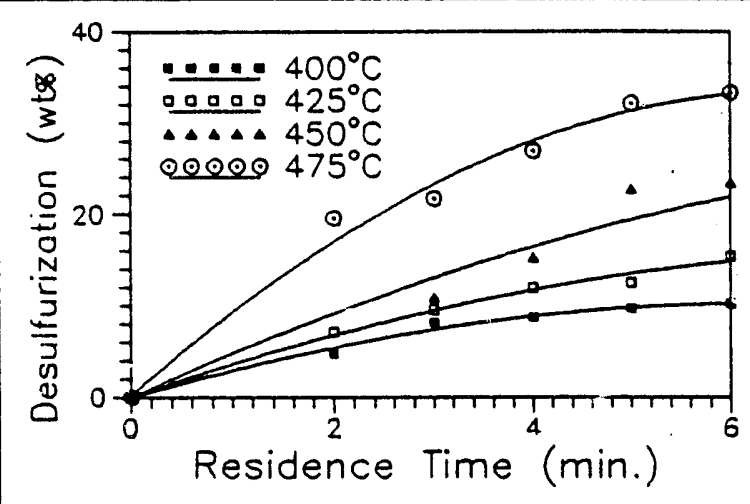

Fig 6. Desulfurization of Ohio \#8 Coal By Pyrolysis (8-16 mesh)

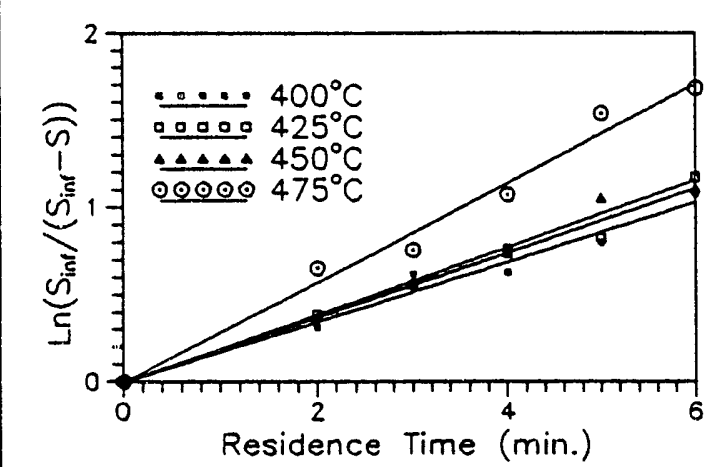

Figure 7. Comparition of Desulfurization Data with First-Order Reoction Assumption

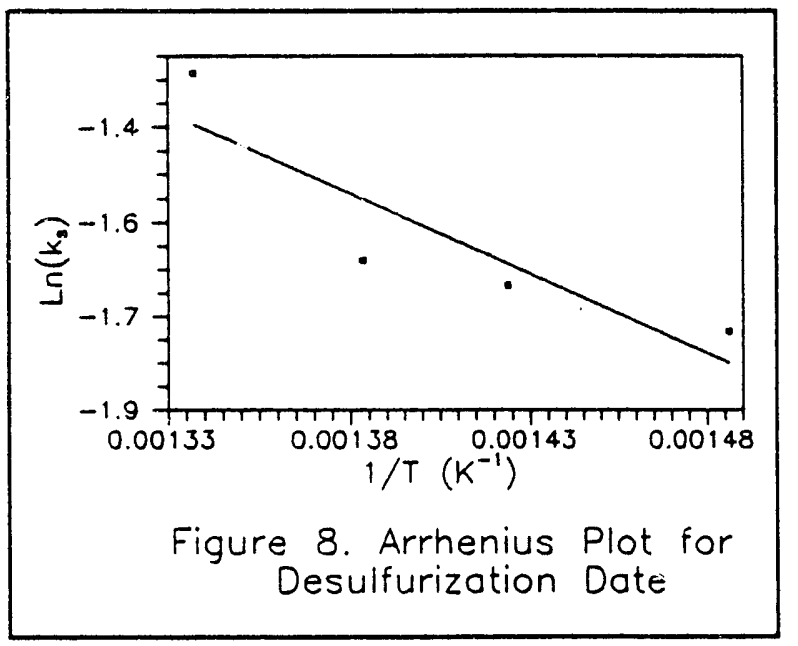
TGA experiment, almost all removable sulfur is released at the temperature $450^{\circ} \mathrm{C}$. The experimental result can be explained by using the same description as above.

4) The Sulfur Removal Efficiency of $\mathrm{CaO}$ in Dual-Screw Feeder

The preliminary experiments show that the $\mathrm{CaO}$ sorbent has very high sulfur removal efficiency in this dual-screw feeder reactor. It is seen that, from the data listed in Table 7 , the sulfur concentration of gas which results from pyrolysis process in inner tube and flows through the outer tube where it reacts with $\mathrm{CaO}$ pellets becomes undetectable. This good result indicates that the sulfur-containing gas could be thoroughly cleaned with $\mathrm{CaO}$ pellets under experimental conditions.

5) The Effect of Coal Particle Size on Pyrolysis The result of pyrolysis production distribution with different coal particle sizes is listed in Table 8. It is clearly seen that the coal particle size has no effect on the pyrolysis kinetics. From the TGA experiments(which will be discussed later), it is known that most of the volatile releases at the temperature higher than about $450^{\circ} \mathrm{C}$ which is the coal swelling point. This means the coal pyrolysis reaction is very slow before the coal particle swells. This observation can be used to explain the result that the coal particle size has no effect on pyrolysis. At a temperature below $450^{\circ} \mathrm{C}$, because the reaction is very slow, little difference of product distribution can be seen when different coal particle sizes are used. When reaction take places at a temperature above $450^{\circ} \mathrm{C}$, all coal particles are swelled, so the difference disappears.

\section{6) The Effect of Coal Particle Size on Desulfurization}

The result of sulfur distribution with different ccal particle size is shown in Table.9. It is observed that the coal particle size also has no effect on the desulfurizaton under the experimental conditions. It is known that, from
ulfur is released at the temperature $450^{\circ} \mathrm{C}$. The 


\section{7) The TGA experimental result}

The TGA experimental result is shown in Fig.8. At the beginning of the reaction, temperature is lower, the mioisture releases first. When the temperature reaches to $450^{\circ} \mathrm{C}$, the pyrolysis reaction becomes very fast and the weight $\%$ of char reaches to the steady value(about $68 \%$ ) if a short time, which indicates that the limiting conversion at $500^{\circ} \mathrm{C}$ is $32 \%$. It is clear that most of the volatiles is released at the coal swelling point.

Fig. 9 is the $\mathrm{H}_{2} \mathrm{~S}$ concentration response of the pyrolysis gas. It is seen that the peak appears at time $=8$ minutes corresponding to the temperature of $450^{\circ} \mathrm{C}$. This indicate the temperature of $450^{\circ} \mathrm{C}$ is important for the coal pyrolysis and desulfurization. It is needed to study the coal behavior at this point.

\section{PLANNED FUTURE WORK}

The following works are planned for the next year of the project:

(a) Continued experiments on dual-screw feeder to study the reaction of $\mathrm{CaO}$ with $\mathrm{H}_{2} \mathrm{~S}$.

(b) Study of the Kinetics of the reaction of $\mathrm{CaO}$ with $\mathrm{H}_{2} \mathrm{~S}$ by using TGA.

(c) Evaluation of the combustion characteristics of char and gas products.

(d) Economic evaluation and scale-up design.

\section{UNEXPECTED PROBLEMS ENCOUNTERED}

Due to increased friction between the inner screw and the tube wall during a longer operating time ( $>4$ hours) at an elevated temperature above $600 \mathrm{C}$, the inner screw was twisted and broken at the location where the heat is first applied while coal particles move along the screw. With a closer examination of the broken screw, it was determined that some corrosion had taken place as well as the metal fatigue and stress. The corrosion may have been caused by mostly the oxidation when some air was trapped within a coal pile.

The following corrective actions are planned at this time.

1) A new improved design for a thicker diameter of screw shaft is being made..

2) A less shallow pitch will be used for the inner screw to lessen the friction and the travel length of coal particles. This will jrevent the "injection molding" effect of coal particles.

3) The same rotational torque will be applied to the both ends of screw shaft by a set of two identical chain drives.

4) The role of limited oxidation may have some beneficial effects in terms of the additional heat needed for pyrolysis and the softening of swelled coal particles. This effects will be carefully examined in the coming year. 


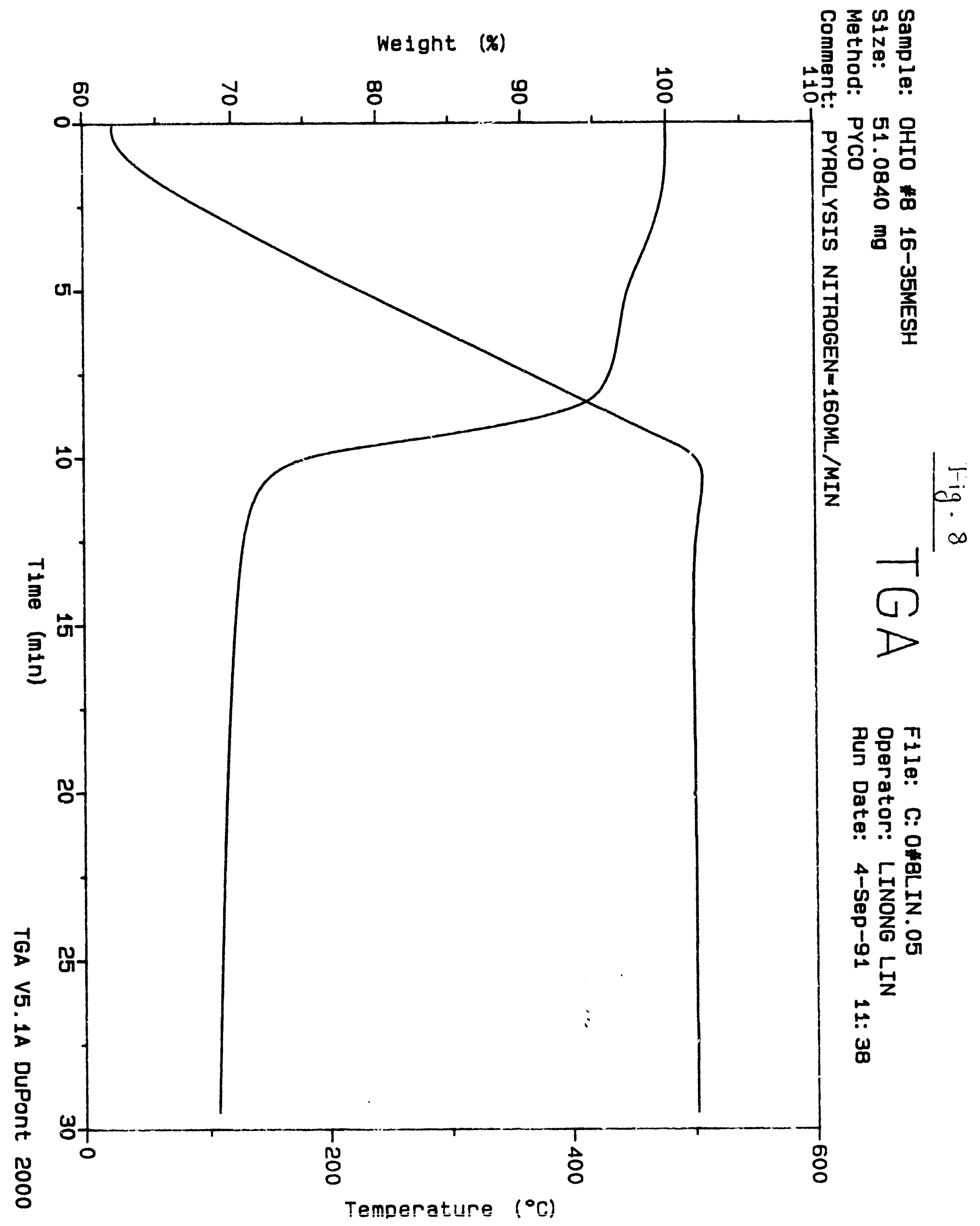



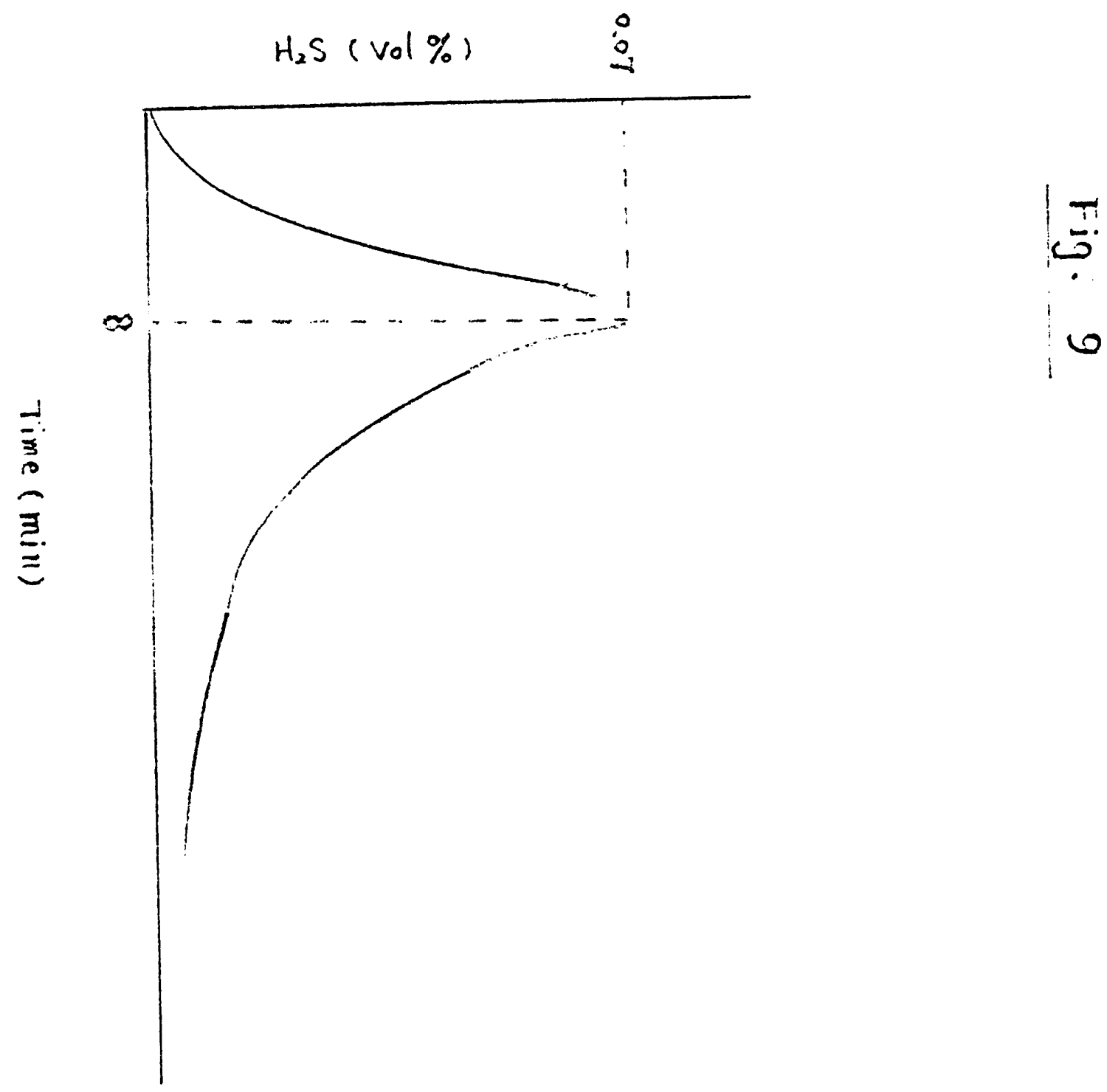
TABLE 1. Pyrolysis Product Distribution of OHIO \#8 Coal (8-16 mesh)

\begin{tabular}{|c|c|c|c|c|c|}
\hline \multicolumn{6}{|c|}{ Temperature $=400^{\circ} \mathrm{C}$} \\
\hline \multirow{2}{*}{$\begin{array}{l}\text { Residence } \\
\text { Time } \\
\text { (min.) }\end{array}$} & \multicolumn{3}{|c|}{ Product Distribution(wt\%) } & \multirow{2}{*}{ Total } & \multirow{2}{*}{$\begin{array}{c}\text { Devolatilization } \\
\text { (wt\%) }\end{array}$} \\
\hline & Char & $\operatorname{Tar}$ & Gas & & \\
\hline 2 & 96.9 & 1.2 & 2.4 & 100.5 & 3.1 \\
\hline 3 & 95.6 & 2.1 & 3.4 & 101.1 & 4.4 \\
\hline 4 & 94.4 & 2.6 & 3.6 & 100.6 & 5.6 \\
\hline 5 & 93.3 & 3.5 & 3.9 & 100.7 & 6.7 \\
\hline 6 & 92.3 & 4.0 & 4.0 & 100.3 & 7.7 \\
\hline \multicolumn{6}{|c|}{ Temperature $=425^{\circ} \mathrm{C}$} \\
\hline 2 & 94.7 & 1.6 & 3.0 & 99.3 & 5.3 \\
\hline 3 & 93.2 & 2.0 & 4.2 & 99.4 & 6.8 \\
\hline 4 & 91.3 & 2.3 & 5.1 & 98.7 & 8.7 \\
\hline 5 & 89.4 & 4.1 & 4.5 & 98.0 & 10.6 \\
\hline 6 & 88.5 & 3.9 & 5.2 & 97.6 & 11.5 \\
\hline \multicolumn{6}{|c|}{ Temperature $=450^{\circ} \mathrm{C}$} \\
\hline 3 & 89.6 & 5.0 & 7.5 & 102.1 & 10.4 \\
\hline 4 & 88.1 & 4.0 & 7.9 & 100.0 & 11.9 \\
\hline 5 & 86.3 & 4.1 & 9.7 & 100.1 & 13.8 \\
\hline 6 & 84.4 & 6.0 & 9.6 & 100.0 & 15.6 \\
\hline \multicolumn{6}{|c|}{ Temperature $=475^{\circ} \mathrm{C}$} \\
\hline 2 & 84.3 & 2.7 & 12.7 & 97.7 & 15.7 \\
\hline 3 & 83.4 & 7.1 & 9.6 & 100.1 & 16.6 \\
\hline 4 & 75.0 & 8.5 & 16.5 & 100.0 & 25.0 \\
\hline 5 & 74.2 & 8.7 & 17.2 & 100.1 & 25.8 \\
\hline 6 & 72.6 & 8.6 & 16.7 & 97.9 & 27.4 \\
\hline
\end{tabular}


TABLE 2. Kinetics Parameters of Pyrolysis

\begin{tabular}{||c|c|c|c|c|}
\hline \hline Ter.sperature $\left({ }^{\circ} \mathrm{C}\right)$ & 400 & 425 & 450 & 475 \\
\hline $\mathrm{X}_{\text {inf }}$ & 0.167 & 0.198 & 0.216 & 0.336 \\
\hline $\mathrm{k}(1 / \mathrm{min})$ & 0.101 & 0.145 & 0.209 & 0.290 \\
\hline
\end{tabular}

TABLE 3. Sulfur Content in Char

\begin{tabular}{|c|c|c|c|c||}
\hline \multirow{2}{*}{$\begin{array}{c}\text { Residence } \\
\text { Time } \\
\text { (min.) }\end{array}$} & \multicolumn{4}{|c|}{ Sulfur Content in Char (wt. \%) } \\
\cline { 2 - 5 } \cline { 3 - 5 } & $400^{\circ} \mathrm{C}$ & $425^{\circ} \mathrm{C}$ & $450^{\circ} \mathrm{C}$ & $475^{\circ} \mathrm{C}$ \\
\hline 2 & 3.11 & 3.22 & & 3.01 \\
\hline 3 & 3.03 & 3.06 & 3.14 & 2.98 \\
\hline 4 & 3.06 & 3.04 & 3.03 & 3.07 \\
\hline 5 & 3.05 & 3.08 & 2.82 & 2.89 \\
\hline 6 & 3.02 & 3.01 & 2.86 & 2.90 \\
\hline
\end{tabular}

TABLE 4. $\mathrm{H}_{2} \mathrm{~S}$ Concentration in Pyrolysed Gas

\begin{tabular}{|c|c|c|c|c||}
\hline \multirow{2}{*}{$\begin{array}{c}\text { Residence } \\
\text { Time } \\
\text { (min.) }\end{array}$} & \multicolumn{4}{|c|}{$\mathrm{H}_{2} \mathrm{~S}$ in gas (volume \%) } \\
\cline { 2 - 5 } & $400^{\circ} \mathrm{C}$ & $425^{\circ} \mathrm{C}$ & $450^{\circ} \mathrm{C}$ & $475^{\circ} \mathrm{C}$ \\
\hline 2 & 1.13 & 2.91 & & 4.08 \\
\hline 3 & 1.08 & 3.03 & 3.91 & 4.06 \\
\hline 4 & 1.16 & 2.97 & 3.90 & 4.06 \\
\hline 5 & 1.10 & 3.07 & 3.76 & 4.00 \\
\hline 6 & 1.17 & 3.04 & 3.81 & 4.04 \\
\hline Average & 1.13 & 3.00 & 3.85 & 4.05 \\
\hline
\end{tabular}


TABLE 5. Sulfur Distribution in Pyrolysis Products of OHIO \#8 Coal (8-16 mesh)

\begin{tabular}{|c|c|c|c|c|}
\hline \multicolumn{5}{|c|}{ Temperature $=400^{\circ} \mathrm{C}$} \\
\hline \multirow{2}{*}{$\begin{array}{l}\text { Residence } \\
\text { Time } \\
\text { (min.) }\end{array}$} & \multicolumn{3}{|c|}{ Sulfur Distribution(wt\%) } & \multirow{2}{*}{$\begin{array}{c}\text { Desulfurization } \\
(w t \%)\end{array}$} \\
\hline & In Char & In $\mathrm{Tar}^{*}$ & In Gas & \\
\hline 2 & 95.3 & 3.83 & 0.87 & 4.7 \\
\hline 3 & 91.9 & 6.90 & 1.20 & 8.1 \\
\hline 4 & 91.8 & 7.27 & 1.43 & 8.2 \\
\hline 5 & 90.3 & 8.29 & 1.41 & 9.7 \\
\hline 6 & 89.4 & 8.56 & 1.64 & 10.6 \\
\hline \multicolumn{5}{|c|}{ Temperature $=425^{\circ} \mathrm{C}$} \\
\hline 2 & 96.9 & 0.26 & 2.84 & 7.1 \\
\hline 3 & 90.5 & 5.30 & 4.20 & 9.5 \\
\hline 4 & 88.1 & 6.76 & 5.14 & 11.9 \\
\hline 5 & 87.5 & 7.71 & 4.79 & 12.5 \\
\hline 6 & 84.6 & 9.84 & 5.56 & 15.4 \\
\hline \multicolumn{5}{|c|}{ Temperature $=450^{\circ} \mathrm{C}$} \\
\hline 3 & 89.2 & 0.98 & 9.82 & 10.8 \\
\hline 4 & 84.8 & 5.41 & 9.79 & 15.2 \\
\hline 5 & 77.3 & 4.38 & 18.32 & 22.7 \\
\hline 6 & 76.6 & 5.08 & 18.37 & 23.4 \\
\hline \multicolumn{5}{|c|}{ Temperature $=475^{\circ} \mathrm{C}$} \\
\hline 2 & 80.5 & 2.42 & 17.08 & 19.5 \\
\hline 3 & 78.4 & 8.00 & 13.60 & 21.6 \\
\hline 4 & 73.17 & 2.99 & 23.81 & 26.8 \\
\hline 5 & 68.1 & 7.38 & 24.52 & 32.0 \\
\hline 6 & 66.8 & 6.44 & 26.73 & 33.2 \\
\hline
\end{tabular}

* Obtained by difference 
TABLE 6. Kinetics Parameters of Desulfurization

\begin{tabular}{|c|c|c|c|c||}
\hline \hline Temperature $\left(^{\circ}\right)$ & 400 & 425 & 450 & 475 \\
\hline $\mathrm{S}_{\text {inf }}$ & 17.6 & 22.3 & 34.9 & 40.8 \\
\hline $\mathrm{k}_{\mathrm{s}}(1 / \mathrm{min})$. & 0.171 & 0.185 & 0.193 & 0.284 \\
\hline
\end{tabular}

TABLE 7. The Sulfur Removal Efficiency of $\mathrm{CaO}$ pellets in Dual-Screw Feeder

\begin{tabular}{||c|c|c|c|c||}
\hline \multirow{2}{*}{$\begin{array}{c}\mathrm{H}_{2} \mathrm{~S} \text { concentration } \\
\text { of Pyrolysis gas } \\
\text { (Volume \%) }\end{array}$} & \multicolumn{4}{|c|}{ Temperature $\left({ }^{\circ} \mathrm{C}\right)$} \\
\cline { 2 - 5 } & 400 & 425 & 450 & 475 \\
\hline Before Reacted With $\mathrm{CaO}$ & 1.17 & 3.04 & 3.81 & 404 \\
\hline After Reacted With $\mathrm{CaO}$ & 0.00 & 0.00 & 0.00 & 0.00 \\
\hline
\end{tabular}

* Residence Time: Coal particles (8-16 mesh) $6 \mathrm{~min}$. $\mathrm{CaO}$ Pellets (8-16 mesh) $80 \mathrm{~min}$.

TABLE 8. Effect of Coal Particle Size on Pyrolysis

\begin{tabular}{|c|c|c|c|c|c|c|c|c|c|c|}
\hline \multicolumn{2}{|c|}{ Particle Size } & \multicolumn{3}{|c|}{$4-8$ mesh } & \multicolumn{3}{|c|}{$8-16$ mesh } & \multicolumn{3}{|c|}{$16-35$ mesh } \\
\hline \multirow{2}{*}{$\mathrm{T}\left({ }^{\circ} \mathrm{C}\right)$} & \multirow{2}{*}{$\begin{array}{c}\mathrm{Rt} \\
(\mathrm{min})\end{array}$} & \multicolumn{9}{|c|}{ Product Distribution (wt\%) } \\
\hline & & Char & Tar & Gas & Char & Tar & Gas & Char & Tar & Gas \\
\hline 400 & 3 & 95.1 & 2.3 & 3.5 & 95.6 & 2.1 & 3.4 & 95.4 & 2.0 & 3.4 \\
\hline 400 & 6 & 92.5 & 4.1 & 4.0 & 92.3 & 4.0 & 4.0 & 92.0 & 4.3 & 4.3 \\
\hline 475 & 3 & 83.0 & 7.5 & 9.3 & 83.4 & 7.1 & 9.6 & 83.0 & 7.0 & 9.5 \\
\hline 475 & 6 & 73.0 & 9.0 & 17.0 & 72.6 & 8.6 & 16.7 & 72.9 & 8.5 & 17. \\
\hline
\end{tabular}


TABLE 9. Effect of Coal Particle Size on Desulfurization

\begin{tabular}{||c|c|c|c|c|c|c|c|c|c|c||}
\hline \hline \multicolumn{2}{||c|}{ Particle Size } & \multicolumn{3}{|c|}{$4-8$ mesh } & \multicolumn{3}{c|}{$8-16$ mesh } & \multicolumn{3}{c|}{$16-35$ mesh } \\
\hline \multirow{2}{*}{$\mathrm{T}^{\circ} \mathrm{C}$} & $\begin{array}{c}\text { Rt } \\
\text { (min) }\end{array}$ & \multicolumn{6}{|c|}{ Sulfur Distribution (wt\%) } \\
\cline { 3 - 12 } & Char & Tar & Gas & Char & Tar & Gas & Char & Tar & Gas \\
\hline 400 & 3 & 91.1 & 7.63 & 1.27 & 91.9 & 6.90 & 1.20 & 91.7 & 7.00 & 1.30 \\
\hline 400 & 6 & 90.0 & 8.40 & 1.60 & 89.4 & 8.56 & 1.64 & 89.8 & 8.56 & 1.64 \\
\hline 475 & 3 & 78.1 & 8.70 & 13.2 & 78.4 & 8.00 & 13.6 & 78.0 & 8.60 & 13.4 \\
\hline 475 & 6 & 67.0 & 6.10 & 26.9 & 66.8 & 6.44 & 26.7 & 67.1 & 5.90 & 27.0 \\
\hline
\end{tabular}




\section{SECTION II. DENITRIFICATION}

\section{INTRODUCTION}

Coal is predominantly used as a fuel for the production of electricity. A basic step in the use of coal for power generation is the conversion of the chemical energy stored in coal to thermal energy by combustion. Pollution of the atmosphere arising from coal combustion is a major concern as coal is second to petroleum and natural gas as a source of energy. Although constant attention has been given to the control technology for sulfur dioxide $\left(\mathrm{SO}_{2}\right)$ emissions from coal combustion, little improvement has been made in the emission control of oxides of nitrogen(NOx) even though $75 \%$ of NOx has been reported from fuel-bound nitrogen. This research is concerned with the removal of nitrogen by chemical means, Section 1 will briefly address the origin of coals, NOx emissions from coal combustion, and the concept developed on the removal of nitrogen from coal.

\subsection{Formation and Properties of Coal}

\subsubsection{Formation of Coal}

Coal is an organic sedimentary rock. Most coal is formed from plants that existed in swamps millions of years ago. When the plants died, they fell over into the water or were quickly buried. Burial helped decelerate the plants from decaying to carbon dioxide and water. As buried under increasingly thick inorganic sediments, they were progressively compacted by the effect of overburden pressure through long periods of time. The first stage of coalification involves the formation of peat, then lignite, followed by subbituminous coal, bituminous coal and anthracite. The American Society for Testing and Materials( ASTM ) and The British National Coal Board have established different classification systems based on the amount of fixed carbon, the heating values or the amount of volatile matter of coal. Classification of coal by rank is not the major concern of this research. For background purposes of this research, the chemical composition of coal and its alteration during thermal decomposition are briefly described in section 1.1.2

\subsubsection{Chemical Properties of Coal}

Since coal is derived chiefly from plant matter, it consists mainly of the elements which compose plants. During the decay and metamorphic processes which have caused the formation of coal, a certain proportion of these elements have been lost and their chemical relationships have been changed. The chemistry of coal and its derivatives is a subject of extreme complexity and extensive range. The only derivative taken into account in this section is the product of thermally decomposed coal. Generally, the chief products resulting from the decomposition of coal are char, tar, light and heavy oils, water and a mixture of gases consisting mainly of hydrocarbons and some ammonia $\left(\mathrm{NH}_{3}\right)$, hydrogen cyanide $(\mathrm{HCN})$, meihane $\left(\mathrm{CH}_{4}\right)$, carbon monoxide $(\mathrm{CO})$, carbon dioxide $\left(\mathrm{CO}_{2}\right)$, hydrogen sulfide $\left(\mathrm{H}_{2} \mathrm{~S}\right)$ and hydrogen $\left(\mathrm{H}_{2}\right)$. The relative proportions of the various substances obtained from the same coal depend upon temperature, the pressure and the process used. 


\subsection{Emissions of NOx in Coal Combustion}

Oxides of nitrogen (NOx) emissions from coal combustors have become a major environmental concern. The term 'NOx' refers to the sum of nitric oxide(NO) and nitrogen dioxide $\left(\mathrm{NO}_{2}\right)$. NOx is considered as a contributor to the depletion of stratospheric ozone and to global warming. According to the New Clean Air Act Title IV - Acid Deposition, the Environmental Protection Agency of the United States will be required to issue emission standards for NOx that cut NOx emissions (which are expected to increase in the future) to 2 million tons by January 1, 2000 .

Typically, NOx is formed from three processes duing the combustion of nitrogencontaining coals :

(1) thermal NOx : thermal fixation of atmospheric nitrogen at high temperature within the flame zone

(2) fuel NOx: oxidation of organically fuel-bound nitrogen

(3) prompt NOx : attack of hydrocarbon radicals on molecular nitrogen in the reaction zone and subsequent reactions of the species to form oxygen containing species

While the thermally formed NOx can be technically controlled, the major NOx emissions from coal combustion are related to fuel-bound nitrogen. Experimental results on the conversion of fuel-bound nitrogen to nitric oxide in both diffusion and premixed flames published by Fine $e t$ al.(1974) ${ }^{(1)}$, suggested that fuel-bound nitrogen contributes most of the NOx emissions from fluidized-bed combustors but only a small fraction of the emissions from pulverized-coal flames. Later experiments by Fenimore $(1976)^{(2)}$, Morley $(1976)^{(3)}(1981)^{(6)}$, Hayne $(1977)^{(4)}$, and Altenkirch et al. (1979) ${ }^{[s]}$ indicated that $\mathrm{HCN}$ is the key volatile nitrogen containing intermediate formed during fuel-nitrogen combustion. Another study by Vogt et al. $(1978)^{1 n}$ using a model to explain the effect of devolatilization on both coal nitrogen conversion and NOx formation

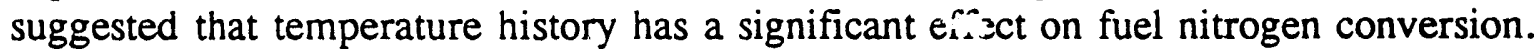

\subsection{The Concept of Coal Denitrification}

Nitrogen is an essential nutrient for all living organisms. The primary source of this nitrogen is the atmosphere. However, nitrogen is not useful to most organisms until it is fixed, mainly by the action of nitrogen-fixing bacteria. These microscopic organisms live in the soil and on the roots of certain plants. The bacteria chemically change nitrogen from the air into nitrogen compounds which are vital to the growth of all plants (i.e. nitrification). Since coal sediments result from living organisms, bacterial action initially decomposed those organisms resulting in the release of gases such as $\mathrm{CH}_{4}, \mathrm{H}_{2} \mathrm{O}$ and $\mathrm{CO}_{2}$. The residuals gradually became concentrated in carbon content and other elements. It is generally agreed that the nitrogen present in coal comes from plant proteins, from nitrogen-rich bacteria, and from plant alkaloids. Levy et al. $(1978)^{(8)}(1979)^{(9)}$ found that after combustion, coal nitrogen is distributed between the volatiles and the char, and reported that volatile nitrogen compounds accounted for the major fraction of nitric oxide(NO) produced from coal nitrogen. The conversion of char nitrogen to NOx was found to be lower than the corresponding value for volatile nitrogen. Considering that coal-bound nitrogen contributes most of NOx emission, nitrogen content in coal 
will be discussed in section 2.1. The goal of this research is to study the technical feasibility of removing nitrogen(i.e. denitrification ) from coal via chemical reactions.

\section{LITERATURE REVIEW}

The approach used in this research is to decompose coal thermally by a novel auger coal feeder system to release nitrogen during mild pyrolysis processes. In this section, a number of recent studies on coal-bound nitrogen, coal pyrolysis, and models of nitrogen evolution are discussed. When caking or coking are heated in an inert atmosphere to $\sim 350-450^{\circ} \mathrm{C}$, particles soften and become deformable, characteristics which are attributable to plastic substances $^{(10)}$. Pyrolytic decomposition of the coal substance in the $350-450^{\circ} \mathrm{C}$ range results in the formation of volatile gases within the plastic particles, which lead to swelling and the development of small cavities or spaces in the tissues of a coal. The plastic property of coal was used to develop the concept of coal denitrification during mild pyrolysis. As a result of progressive chemical reactions and loss of volatile compounds, the plastic state is a transient phenomenon, even under isothermal conditions, and the agglomerated mass ultimately solidifies into a semicoke, which reverts to char in this research.

\subsection{Nitrogen in Coal}

Nitrogen concentrations in coal have been reported to be in the range of $0.5 \sim 2.0 \%$ by weight. Hauck(1975) ${ }^{(11)}$ reported that coals commonly contain $1-2 \%$ nitrogen, bituminous coal typically contain $1.5 \sim 1.75 \%$ nitrogen, and anthracite generally contain less than $1 \%$ nitrogen. Very little appears to have been reported on the nitrogen forms in coal because there are no method of analysis available for determining the forms of nitrogen in coal. Albert (1967) ${ }^{[2]}$ and Snyder (1969) ${ }^{[13]}$ have showed that most of the nitrogen in heavy oils is in the form of heterocycles and proposed that they are similar to nitrogen components of coal. The two approaches which have produced most of the available information are (1) analysis of coal extracts and (2) analysis of the products of coal depolymerization, e.g., by pyrolysis, oxidation, or hydrogenation. ${ }^{[14]}$

\subsubsection{Nitrogen in Coal Extracts}

Extractions from coal with mineral acids yield amides and amino acids. The acid extracts may contain up to $80 \%$ of the total nitrogen in peat, $20 \%$ in lignite, down to around $3 \%$ in anthracite. Thus, during coalification nitrogen compounds may be converted to heterocyclic forms which are unable to be extracted with mineral acids. Monoamino and diamino acids have been identified in peat, lignite, and subbituminous coal, but no diamino acids have been found in bituminous coals and anthracite. ${ }^{(11)}$ However, the actual behavior of complex nitrogencontaining molecules in an acidic solution is not known. Data from the analysis of coal extracts should always be examined with caution.

\subsubsection{Nitrogen in the Product of Coal Depolymerization}

A variable amount of coal nitrogen is released during coal pyrolysis in the form of ammonia depending predominantly on the pyrolysis temperature and on the moisture content of the gas. The yield of ammonia reaches a maximum at pyrolysis temperatures of $600 \sim 700^{\circ} \mathrm{C}$. 
The presence of water vapor increases the yield of ammonia. On the other hand, nitriles which contain cyano groups could be a major constituent of the nitrogen in coal since they are neutral but react with hydrogen to form bases. Some nitrile polymers form ammonia during pyrolysis as well. The distribution of nitrogen compounds in the products of coal liquefaction is to a large extent similar to the distribution of products in coal pyrolysis. Most of the nitrogen in coal tar and in liquefaction products is bound in pyridines, pyrroles, and organic cyanide-containing compounds(i.e. nitriles). ${ }^{(15)}$ The two major differences are the low concentration of anilines and the presence of a large concentration of carbazoles in the products of liquefaction ${ }^{[16]}$. The data suggest that the majority of the nitrogen is present in two- and three-ring compounds. The absence of anilines in the liquid is not surprising since they are very reactive and, even if present in coal, would have reacted under liquefaction conditions.

Leppälahti and Kurkela (1991) ${ }^{(17)}$ studied the formation of nitrogen compounds and tars in a laboratory scale fluidized bed air gasifier under atmospheric pressure and concluded that a significant part of the fuel nitrogen is converted to $\mathrm{NH}_{3}$ and $\mathrm{HCN}$ in fluidized bed air gasification. Price et al. (1983) ${ }^{[18]}$ measured nitrogen compound concentrations inside a laboratory scale entrained-bed gasifier and found that significant amounts of fuel nitrogen were oxidized to $\mathrm{NO}$ in addition to the formation of $\mathrm{NH}_{3}$ and $\mathrm{HCN}$. Nichols et al. (1987) ${ }^{[19]}$ showed that the quantity of $\mathrm{NH}_{3}$ was increased and that of $\mathrm{HCN}$ reduced by raising the pressure in a high temperature entrained-bed gasifier. In summary, it appears that $50 \sim 75 \%$ of the nitrogen in coal is present in pyridine and quinoline derivatives. The presence of cyano and amino groups has never been fully proven or disproven. The source of the elemental nitrogen formed during coal pyrolysis in high temperature $\left(600 \sim 800^{\circ} \mathrm{C}\right)$ is probably second?ry gas-phase reactions involving ammonia.

\subsection{Coal Pyrolysis}

The continuing need for a more complete understanding of coal pyrolysis phenomena is an accepted fact among every group concerned with either coal combustion or coal conversion to synthetic fuels. As used in this review, the term coal pyrolysis or devolatilization refers to a set of physical and chemical processes which manifest themselves any time coal is heated to temperatures in excess of roughly $300^{\circ} \mathrm{C}$. The processes generally result in the production of various gases, oils, tars, and a carbonaceous char. In many cases of practical interest, the pyrolysis products are but intermediates in processes which ultimately involve complete combustion or gasification. Nevertheless, the nature of the pyrolysis products can be important in determining many features of the processes which occur after the pyrolysis reaction is over.

Coal pyrolysis is important since it is the initial step in most coal conversion processes and is the step which is most dependent on the properties of the coal. In liquefaction processes, pyrolysis controls the initial yield of soluble products and the competitive yield of gas species. The same processes prevail in combustion and gasification. In addition to the importance of pyrolysis in coal processing, analysis of pyrolysis products can supply important information to the structure of the parent coal, and its nonvolatile and volatile products. Recent advances in the pyrolysis research ${ }^{[20-2]}$ present a complicated profusion of results, including the development of a more detailed and accurate pyrolysis model, the acquisition of pyrolysis data for a wide variety of coals under a wide variety experimental conditions, and the release of comparisons 
of model aud experiment ${ }^{[23-27]}$.

\subsubsection{Products of Coal Pyrolysis}

Pyrolysis of coal is generally taken to mean destructive distillation. When coal is heated, a progressive depolymerization occurs which releases volatile materials. At the same time, a number of condensation or repolymerization processes take place to form solid char residue. Not only different coals but the saine coal will produce different pyrolysis liquids depending on any pyrolysis parameter, such as temperature, residence time, pressure, reactor design, and gasphase composition. To be commercially practical, any pyrolysis scheme must be coupled with a way to use the char. In order to select a proper process for pyrolysis-char utilization, both qualitative and quantitative analyses of functional groups are needed to complete a characterization profile of char.

It is known that certain minerals exhibit definite catalytic effects in gasification, and others exhibit catalytic effects in liquefaction. ${ }^{[21}$ Since the mineral content of a char is greater than that of the parent coal, and since its composition is altered from that of the minerals in the coal from which it is derived, it is a fairly open question about the effect of mineral matter on the pyrolysis products. In the meantime, there are lots of critical technical problems and knowledge gaps associated with the liquid products. For instance, there is no method available to identify and quantify the forms of oxygen, sulfur, and nitrogen functionalities in coal pyrolysis liquids. Historically, most pyrolysis liquids which had an end use as fuels were treated with hydrogen. ${ }^{[29]}$ On the other hand, a variety of potentially valuable products can be obtained from low-temperature pyrolysis liquids by a combination of separation techniques that do not consume hydrogen. However, toxicological problems are of enormous significance in the utilization of pyrolysis liquids. Both the combustion of pyrolysis liquids and the transportation and handling has the potential of releasing carcinogens to the environment.

\subsubsection{Mild Pyrolysis of Coal}

All coals release volatile matter when heated. A number of useful experiments for investigating pyrolysis have been performed in flash pyrolysis at heating rates between $10^{2} \sim 10^{4} \mathrm{C} / \mathrm{s}$ at temperatures up to $1800^{\circ} \mathrm{C}$; these provided the basis for developing a general kinetic model of coal pyrolysis and achieving good mass and elemental balances. ${ }^{[23-27]}$ While the flash pyrolysis experiments are excellent for obtaining material balance and minimizing secondary reactions, mild pyrolysis is more desirable to utilize pyrolysis-char, to distinguish the individual sources contribution and to measure separate kinetics.

The primary devolatilization of coal takes place at generally about $350^{\circ} \mathrm{C}$ and is complete at $550^{\circ} \mathrm{C}$. However, it is clear that relatively small quantities of many species are evolved at much lower temperatures( below $200^{\circ} \mathrm{C}$ ), especially under reduced pressure. Loosely bound $\mathrm{H}_{2} \mathrm{O}$ and $\mathrm{CO}_{2}$ molecules are evolved early, followed by more strongly bound molecules of the same species. Recent studies by Fuller $(1979)^{301}$ with mass spectrometric analysis of species devolatilized under vacuum showed that hydrocarbons $\left(\mathrm{C}_{2}, \mathrm{C}_{3}\right.$, and $\left.\mathrm{C}_{4}\right)$ appear above $150^{\circ} \mathrm{C}$, accompanied at above $180^{\circ} \mathrm{C}$ by detectable quantities of aromatics and sulfur-containing species. Studies by Rahman and Vahrman (1971) $)^{(31)}$, Palmer and Vahrman (1972) $)^{\mid 32 !}$, Palmer and Vahrman 
$(1972)^{[33 \mid}$, Watts and Vahrman $(1972)^{[34,35]}$, and Hayatsu et al. $(1977)^{(36]}$ showed that many products canbe distilled into vacuum at $150^{\circ} \mathrm{C}$ from bituminous coal. Generally, pyrolysis occurs above $300^{\circ} \mathrm{C}$, but the thermal cleavage is significant above $400^{\circ} \mathrm{C}$. Through primary devolatilization, the crosslinked network suffers alterations which affect the coal conversion into chars and tars ${ }^{37]}$ including low molecular weight gases. The char features will depend on the starting coal and the operating conditions. If the pyrolysis is carried out under very mild conditions, the converted products will be representative of the original coal matrix.

\subsection{Modeling of Nitrogen Evolution}

A number of empirical pseudo-chemical-rate models which combine pyrolysis/mass transfer have been developed to adequately describe the coal pyrolysis phenomena observed under rapid-heating conditions as in pulverized or fluidized combustion and gasification. Most of the models are capable of predicting the effects of pressure and particle diameter on the composition and properties of volatile products of pyrolysis. In terms of understanding the behavior of nitrogen evolution in this research, the approach which most adequately describes the kinetic of species evolved during mild pyrolysis is that of the weight percentage, $W_{i}$, of nitrogen evolved. It is assumed to be governed by a first-order rate as given in equation 2.3.1,

$$
\frac{d W_{i}}{d t}=k_{i}\left(W_{0}-W_{i}\right)
$$

where $W_{o}$ is the weight percentage of nitrogen evolved at infinite time and $k_{i}$ is a rate constant which may be assumed to be given by the expression below :

$$
k_{i}=A \exp \left(-\frac{E_{i}}{R T}\right)
$$

where $A$ is the rate parameter, $R$ is the universal gas constant, and $E_{i}$ is activation energy. Similar models for devolatilization products have been used by Fitzgerald and van Krevelen $(1959)^{[38]}$. Although the influence of reaction conditions on volatile evolution rate has resulted in the wide variations in rate data as studied by Howard et al. $(1981)^{(39)}$, the derived kinetic expression can be demonstrated for a simple first-order process as weight loss.

\section{Coal Feeder - Pyrolysis System}

To accomplish the goal of this research, the design of the experimental facility had pivotal modifications in order to resolve the problems which were encountered in the initial design. On the other hand, the modified facility was based on the experimental results of the initial facility. This section provides a detailed descriptions of both experimental systems. 


\subsection{Initial Scheme of Coal Feeder}

The coal feeder has been designed to study mild coal pyrolysis under atmosphere pressure. The schematic of the apparatus is presented in the previous quarterly reports. It consists of three principal sections : (1) a coal feed section (2) a heating and temperature control section (3) a residue recovery and analysis section. Considering the corrosive effect on the apparatus by gaseous products, all the parts which might be corroded were made of stainless steel, such as the feed tube, the auger, the sampling tubing, the connectors and the fittings. ihe following is a detailed description of the apparatus.

\section{(1). Feed jection}

This section consists of a V-shaped coal feed hopper connected with a stainless steel feed tube, which has a 1 inch inner diameter, $1 \frac{1 / 4}{4}$ inches outer diameter, and is 3 feet in length( 4 inches is used for a water jacket ). A stainless steel auger was welded onto a $1 / 2$ inch diameter stainless steel shaft that is driven by a 1.5 horse-power variable speed DC motor. The pitch of the screw is $3 / 4$ inches with even spaces along the shaft. A gear reduction motor(Model $4 Z 733 \mathrm{C}$, reduction ratio $30: 1$ ) allows greater control of the process in the high speed range, which the motor is more stable with respect to the r.p.m.'s than at lower speeds. An initial 4inch segment at the driving end was no longer manipulated since a leaking problem was detected ; eventually compressed air was employed to prevent the bearing from being over heated and to keep the hopper cool. The entire feed section is air tight ; nitrogen is entrained into the hopper to provide a reducing or inert environment while coal is conveyed and heated. At the same time, the entrainer, nitrogen will slightly pressurize the hopper to prevent the evolved gases from rolling back. The feed tube is insulated to maintain isothermal condition during coal pyrolysis. The residence time of coal samples inside the feed tube is controlled by adjusting the speed of the driving motor, and is variable from 0.67 to 10 minutes.

\section{(2) Heating and Temperairure Control Section}

The pyrolysis condition is provided by seven band type electrical heaters with a power of 625 watts per heater to heat the feed tube. Five temperature controllers are employed to control these heaters to supply a uniform temperature distribution along the feed tube. The temperature of the feed tube can be varied from 20 to $800^{\circ} \mathrm{C}$ by a Watlow $985 \mathrm{~A}-2 \mathrm{DCO}$ temperature controller/indicator. A multi-channel switch enable monitoring of the temperatur $e$ profiles of each heater to maintain a uniform pyrolysis condition.

\section{(3) Residues Recovery and Analysis Section}

There are three types of pyrolysis products : char, condensable liquids, and gases expected in this experiment. The volatile products were drawn from a $1 / 4$ " sampling port which is mounted on the end of the feed tube. The sampling port is heated to about $220^{\circ} \mathrm{C}$ and insulated to prevent volatile products from condensing inside the tubing to cause blockage. Three condensers are connected in series to ensure complete condensation. The cooled gases are filtered and then directly conducted to both $\mathrm{H}_{2} \mathrm{~S}$ and $\mathrm{H} / \mathrm{C}$ analyzers. Negative pressure provided by a pump at the outlet of the third condenser and the analyzer enables to reduce flow resistance. A dryer and a scrubber bottle containing $500 \mathrm{~mL}$ of a low sodium hydroxide solution was attached forward to the pump to keep the pump from being fouled by $\mathrm{H}_{2} \mathrm{~S}$. Liquid products are 
condensed from the hot gas stream to the three condensers. Residual solids are successively captured by the quench tank while the coal samples are conveyed through the feed tube by the driving auger. A pressure gauge is mounted on the quench tank to monitor the pressure variation of the feed section. An excessive gauge reading might indicate a blockage of the sampling ports or gas vent lines.

\subsection{Modified Scheme of Coal Feeder}

The initial coal feeder was unable to generate a representative amount of condensable products ; this was of critical importance to the mass balance of the pyrolysis research. This problem might have been associated with a blockage of the reconsolidation of volatile products even though the sampling port was heated to over $220^{\circ} \mathrm{C}$. Another problem was caused by the swelling of coal samples. Under very rapid heating condition, the volatile gases are released quickly and reach a sufficiently high pressure to rupture the wall of the coal. For mild heating conditions, the cells of coal can coalesce and particles can swell somewhat before rupture. This swelling resulted in an enormous resistance to conveying the coal samples in the feed tube. Modification of the coal feeder was based on preliminary experimental testing of the initial coal feeder. The critical alterations are addressed in each section of the coal feeder.

\section{(2) Heating and Temperature Control Section}

The testing results of the first phase indicated that the longer residence times which were used in the initial coal feeder did not have a significant effect on nitrogen evolution. In addition, the longer feed tube caused more resistances to swelling. The modified tube used in the second phase test was designed to have residence times varying from 20 to 155 seconds. The dimension of the feed tube was 2 feet in length and only four band type electrical heaters and three temperature controllers were employed.

\section{(3) Residues Recovery and Analysis Section}

The sampling port of volatile products was no longer heated. One of three condensers which were connected in series to ensure complete condensation was mounted very close in order to the sampling port to capture volatile products immediately as the hot gas stream came out of the sampling port. All the non-condensable species were collected in air sampling bags, which were placed one bag at a time inside a sealed box with a slightly negative pressure. The condensers retained practically all of the condensable tar and liquids. The air bag provided a reliable method of capturing all of the non-condensables during a typical run.

\section{DENITRIFICATION TESTS AND ANALYSIS}

The denitrification experiments were conducted in a novel coal feeder in two phases : the initial and then the modified designs of the coal feeder. Table 4.1.1 lists the schedules of each run in each phase. 
Table 4.1.1 Experimental Schedule of Denitrification Tests

\begin{tabular}{||l|l|l|l|l|l|l||}
\hline & \multicolumn{6}{|c||}{ Residence Time( minute ) } \\
\hline Temp $\left({ }^{\circ} \mathrm{C}\right)$ & 375 & 400 & 425 & 450 & 475 & 500 \\
\hline \hline \multirow{3}{*}{$\begin{array}{l}\text { 1st phase } \\
\text { desigrial }\end{array}$} & 1.00 & 1.00 & 0.97 & 0.67 & & \\
\cline { 2 - 8 } & 1.13 & 1.80 & 1.27 & 1.17 & & \\
\cline { 2 - 8 } & 1.80 & 2.50 & 1.80 & 1.40 & & \\
\cline { 2 - 7 } & 2.50 & 3.30 & 2.00 & 1.80 & & \\
\cline { 2 - 7 } & 4.60 & 7.70 & 2.50 & 2.55 & & \\
\cline { 2 - 7 } & 7.00 & 10.0 & 4.80 & 4.60 & & \\
\hline \multirow{3}{*}{$\begin{array}{l}\text { 2nd phase } \\
\text { design }\end{array}$} & & 1.00 & 1.00 & 1.00 & 1.00 & 1.00 \\
\cline { 2 - 7 } & & 1.50 & 1.50 & 1.50 & 1.50 & 1.50 \\
\hline \hline
\end{tabular}

This section includes a detailed description of sample material, the experimental procedure, and the analyses involved in the denitrification tests. Most of the analyses were carried out by ASTM Standard ${ }^{|(0)|}$ and Standard Methods ${ }^{(4) \mid}$.

\subsection{Sample Coal}

In comparison to the geologic and geographic distribution of coal in United States, coals in Ohio are considered to be bituminous coals. An Ohio No.8 coal supplied Uy R \& F Coal Company, (Columbus, Ohio) was subjected to the coal feeder in this research. The ample coal was crushed with a hammer to a suitable sizes for a mechanic grinder, and siever' to 3.3 millimeter particle size before use. The proximate analysis of the Ohio No.8 coal, as provided by the supplier, is listed in Table 4.1.2. 
Table 4.1.2 The Proximate Analysis of Ohio No.8 Coal

\begin{tabular}{||l|l|l|}
\hline \hline Item & As Received & Dry Base \\
\hline \hline Fixed Carbon(wt \%) & 41.39 & 43.79 \\
\hline Volatile(wt \%) & 37.55 & 39.73 \\
\hline Moisture(wt \%) & 5.49 & --- \\
\hline Ash(wt \%) & 12.12 & 12.82 \\
\hline Sulfur(wt \%) & 3.45 & 3.65 \\
\hline Heating Value(Btu/lb) & 12007 & 12704 \\
\hline Heating Value (d.a.f base ) & 14573 \\
\hline
\end{tabular}

Source : R \& F Coal Company

\subsection{Testing Procedure}

\subsubsection{System Operation}

At the beginning of this experiment, nitrogen was entrained into the feed tube and quench tank to obtain the inert environment. Then, the feed tube was heated to a predetermined temperature until an isothermal condition was maintained. Sample coal and steel balls(2nd phase) were preweighed and mixed together to load into the feed tube. The sample was fed at a slow and constant rate by the driving motorin order to avoid fluctuation in the performance of the screw as well as to maintain the isothermal condition.

In the first phase, nitrogen gas was entrained into the hopper at a rate of $250 \mathrm{c.c} . / \mathrm{min}$ in order to slightly pressurize the hopper to keep evolved gases from flowing back. Because of the alterations to the gas sampling system, the entrained nitrogen was not employed in the second phase. The pyrolysis reaction was assumed to stop immediately as the char residue fell into the quench tank. After pyrolysis was complete, a known weight(about 75 grams) of steel balls were added into the feed tube to " clean out " the inside of the tube to ensure that no unreacted sample coal or char residue had stuck on the walls of the tube. This approach greatly improved the problems of coal swelling and mass balance which were encountered in the first phase.

\subsubsection{Sampling of Residues}

Char residue was caught by an aluminum sheet inside the quench tank. A magnet was used to separate the steel balls and char residue in the second phase testing. Both char and balls were weighed immediately after pyrolysis in order to prevent moisture absorbed from the air from effecting the results. Char was stored in a sealed glass jar for analysis and balls were recycled for next run. Since steel balls were assumed not to react and decompose, the weight difference was added to the weight of the char. 
Condensable liquids were condensed in three condensers; the first condenser was equipped very closely to the volatile products sampling port in order to eliminating the problem due to blockage of the sainpling line which occurred during the first phase testing. When testing the collection system, it was found that the third condenser contained uncounterable amount of condensable yield from pyrolysis. Tar and liquid( water ) were carefully separated by syringes, weighed, and stored in sealed glass jars in order to prevent the light-weight volatiles from evaporating.

Non-condensables were analyzed by on-line $\mathrm{H}_{2} \mathrm{~S}$ and $\mathrm{H} / \mathrm{C}$ analyzers in the first phase testing and were collected in air bags which were placed one bag at a time inside of a sealed box with a slightly negative pressure supply in the second phase testing. After being weighed, the sample could be conducted to a specific valve in order to release the gaseous products from the air bags. Aithough there was a gas chromatograph equipped with a thermal conductivity detector and an integrator, the two columns in series used were unable to separate the hydrogen $(\mathrm{HCN})$ and ammonia $\left(\mathrm{NH}_{3}\right)$, which were the proposed nitrogen-containing species in the gaseous products. Thus, the $\mathrm{HCN}$ and $\mathrm{NH}_{3}$ were collected by a $1 \mathrm{~N} \mathrm{NaOH}$ and a $2 \mathrm{~N}_{2} \mathrm{SO}_{4}$ solution, respectively. The amounts of $\mathrm{HCN}$ and $\mathrm{NH}_{3}$ were determined by titrating in accordance with Standard Methods for the Examinations of Water and Wastewater ${ }^{(4) \mid}$.

\subsection{Experimental Analysis}

\subsubsection{Decermination of Nitrogen in Residues}

The method usually employed for the determination of nitrogen content in parent coal and its residue, char, tar and water in this denitrification test is the modified Kjeldahl-Gunning method $^{[40}$. One gram of coal is placed in a $800 \mathrm{~mL}$ Kjeldahl flask together with $30 \mathrm{~mL}$ of concentrated sulfuric acid, 7 to 10 grims of potassium sulfate, and 0.6 to 0.8 gram of mercury. The solution should be boiled until all the coal is oxidized and the solution has become practically colorless. The boiling requires at least 2 hours after the solution has reached the straw-colored stage. The total time of digestion is 3 to 4 hours and much more for coke and anthracite.

The solution is allowed to cool and diluted to about $400 \mathrm{~mL}$ with cold water. Then, 100 $\mathrm{mL}$ sodium hydroxide solution which contains potassium sulfide is carefully and slowly added into the coolsd flask. The Kjeldahl flask is at once connected wit'? the condenser, and the ammonia is distilled over into a measured amount of boric acid solution. The distillation is continued until 250 to $300 \mathrm{~mL}$ has passed over. The distillate is then titrate with $0.2 \mathrm{~N}$ sulfuric acid solution.

\subsubsection{The Determination of Moisture}

A substitutive method was carried out by a regular oven which was capable of maintaining the temperature of $104 \sim 110^{\circ} \mathrm{C}$ to heat the $250 \mu \mathrm{m}$ coal and char samples in the capsules for 2 hours then cooled in a desiccator and weighed to calculate the moisture.

\subsubsection{The Determination of Ash}


The ash in coal or coke is a non-combustible mixture. Two apparatus are needed for analyze the ash content in coal or coke : (1) A gas or electric muffle furnace with a good air circulation and being capable oi maintaining a regular temperature between 700 and $750^{\circ} \mathrm{C}(2)$ Porcelain capsules $7 / 8 "$ deep and $13 / 4 "$ inches in diameter.

The porcelain capsules, containing the dried coal from the moisture determination, arer placed in a cold muffle furnace or on the hearth at a low temperature and gradually heated to redness at such a rate as to avoid loss of particles of the sample from the rapid expulsion of the volatile matter. The capsules are cooled in a desiccator and weighed.

\section{RESULTS AND DISCUSSION}

This section contains the results of both the first and the second phases of the denitrification tests and the data relating to the devolatilization. Variatles that influence devolatilization include temperature, residence time, pressure, particle size and coal type. Since the condition of this study was under the atmosphere pressure and a certain size of an Ohio No. 8 coal, discussion in this section will be addressed on the effects of residence time, pyrolysis temperature. In addition, the kinetics of both devolatilization and denitrification in mild coal pyrolysis were discussed to support the results of the experiment.

\subsection{Devolatilization and Denitrification}

The solid residues of pyrolysis, chars, have provided important information relating to denitrification, although a material balance was unable to be obtained for the first phase testing because of a blockage of the sampling port. The samples of coal were manipulated in the coal feeder at temperatures varied between $375 \sim 450^{\circ} \mathrm{C}$ with residence times varying from $1 \sim 8$ minutes. In the second phase, temperatures varied from $400 \sim 500^{\circ} \mathrm{C}$ with residence time varying from $1.0 \sim 2.0$ minutes. The particle size of coal had an average diameter 3.3 millimeters. During the pyrolysis, the heating causes thermal rupture of bonds and volatile fragments escape from the coal. The devolatilization is defined as equation (5.1.1) :

$$
\operatorname{DeVol}(\% \text { daf })=\left(1-\frac{W_{\text {char }}}{W_{\text {coal }}}\right) 100
$$

where $W_{\text {cher }}$ and $W_{\text {coul }}$ are the mass of the char and the coal expressed on dry, ash-free basis. The denitrification is presented by percentage and is calculated by equation (5.1.1).

$$
\text { DeNitri }(\% \text { daf })=\left(1-\frac{W_{\text {char }} N_{\text {char }}}{W_{\text {coal }} N_{\text {coal }}}\right) 100
$$

Since the nitrogen evolution has been assumed to be governed by a first order reaction, the denitrification is defined as the difference between the nitrogen in coai $\left(W_{\text {cosed }} N_{\text {coal }}\right)$ and the nitrogen in char ( $W_{\text {char }} N_{\text {char }}$ ) normalized to the nitrogen in coal, where $W_{\text {coul }}$ and $W_{\text {ctar }}$ are the mass of the coal and the char ; $N_{\text {coal }}$ and $N_{\text {ctar }}$ are the nitrogen contents of coal and char expressed on 
dry, ash-free basis, respectively.

\section{(1) First Phase Testing}

The results of devolatilization and denitrification from the first phase testing shown in Table 5.1.1 indicate that the rates of devolatilization and denitrification are very close.

Table 5.1.1 Devolatilization and Denitrification in 1st Phase Testing

\begin{tabular}{|c|c|c|c|}
\hline $\begin{array}{c}\text { Pyrolysis } \\
\text { Temperature }\left({ }^{\circ} \mathrm{C}\right)\end{array}$ & $\begin{array}{r}\text { Residence } \\
\text { Time(minute) }\end{array}$ & $\begin{array}{r}\text { Devolatilization } \\
(\% \text { daf })\end{array}$ & $\begin{array}{l}\text { Denitrification } \\
\text { ( \% daf ) }\end{array}$ \\
\hline \multirow[t]{5}{*}{375} & 1.00 & 1.46 & 4.37 \\
\hline & 1.13 & 4.61 & 4.23 \\
\hline & 1.80 & 5.85 & 4.16 \\
\hline & 4.60 & 6.25 & 6.84 \\
\hline & 7.00 & 6.46 & 8.54 \\
\hline \multirow[t]{5}{*}{400} & 1.00 & 4.86 & 2.12 \\
\hline & 2.50 & 8.11 & 2.89 \\
\hline & 3.30 & 11.81 & 4.51 \\
\hline & 7.70 & 16.95 & 9.77 \\
\hline & 10.00 & 17.63 & 9.99 \\
\hline \multirow[t]{5}{*}{425} & 0.97 & 7.13 & 3.57 \\
\hline & 1.27 & 13.97 & 10.66 \\
\hline & 1.80 & 12.28 & 10.42 \\
\hline & 2.50 & 13.15 & 10.99 \\
\hline & 4.80 & 16.64 & 12.44 \\
\hline \multirow[t]{5}{*}{450} & 1.17 & 9.89 & 5.76 \\
\hline & 1.40 & 13.25 & 8.23 \\
\hline & 1.80 & 14.20 & 10.51 \\
\hline & 2.55 & 21.34 & 12.93 \\
\hline & 4.60 & 25.37 & 16.67 \\
\hline
\end{tabular}


residence time. The results show that devolatilization and denitrification have the similar tendency during the tests of different temperatures. Without a mass balance, it is assumed that the inaccurate measurements of weight loss during pyrolysis result in a slight fluctuation at temperatures of 375 and $425^{\circ} \mathrm{C}$. By equation 5.1.2, the denitrification is determined by the ratio of both mass and nitrogen content between char and parent coal. Nitrogen content in char in each testing presented on Table 5.1.2 show that nitrogen content does not change much in char even pyrolysis run at longer residence time. Nitrogen content in the tests of longer residence time slightly increases due to the nitrogen-free gas products evolved. The conclusion was drawn that devolatilization dominates the denitrification in these pyrolysis tests. Higher pyrolysis temperatures and longer residence time do have more devolatilization and denitrification in most of the tests. However, it is believed that devolatilization is more dependent on pyrolysis temperature than on residence time in this mild pyrolysis study.

\section{(2) Second Phase Testing}

The distribution of pyrolysis products from the second phase testing is shown in Table 5.1.3 as the weight percentage of the total residue of each experimental run. The range of the mass balances were from the range of $92 \% \sim 101 \%$ compared to the parent coal. It is believed that a mass balance had been achieved to a reliable extent. Figures 5.1.5, 5.1.6, and 5.1.7 illustrate the results from the mass balances of three different residence times.

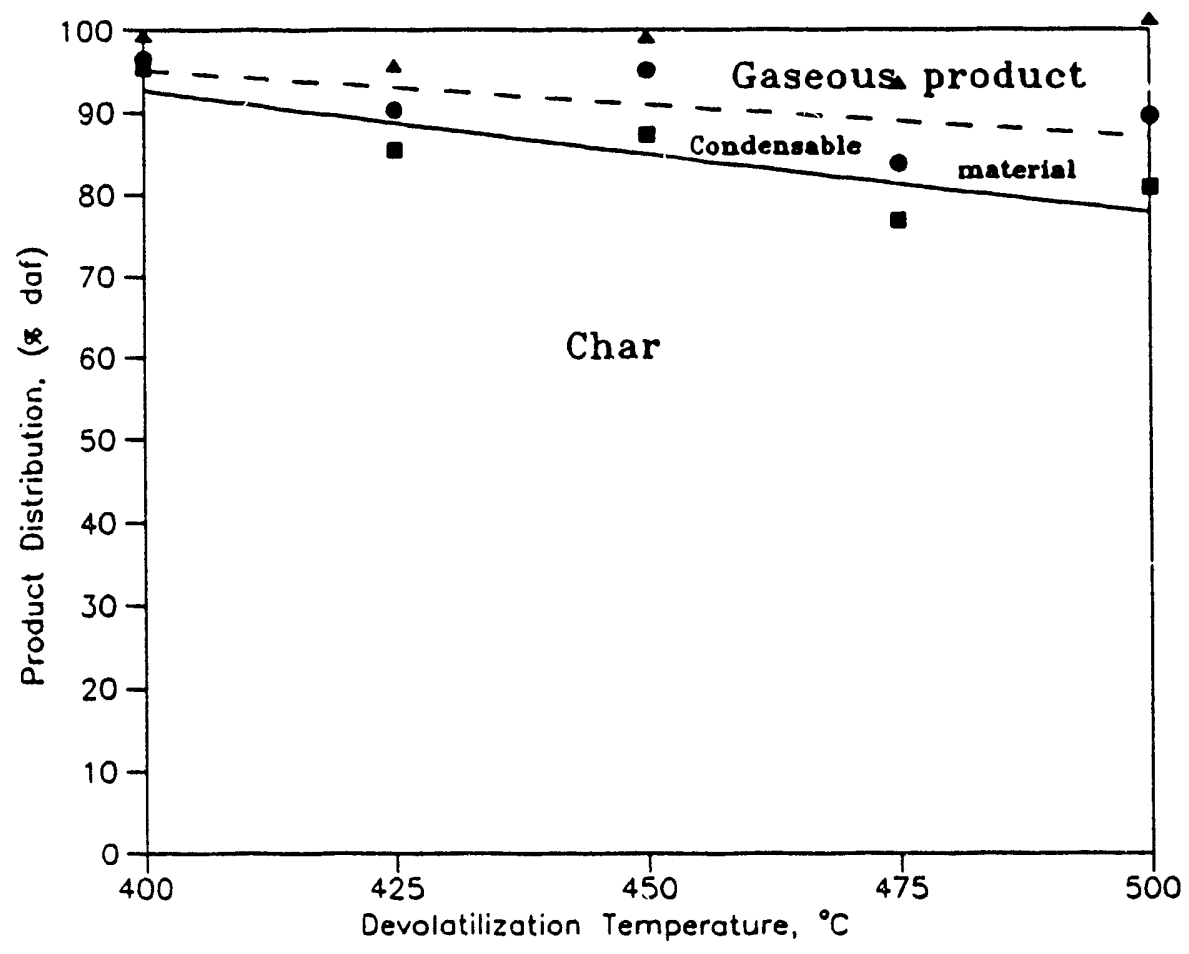

Figure 5.1.5 Residue composition of 300 grams coal at different pyrolysis temperatures with a residence time of 1.0 minute 


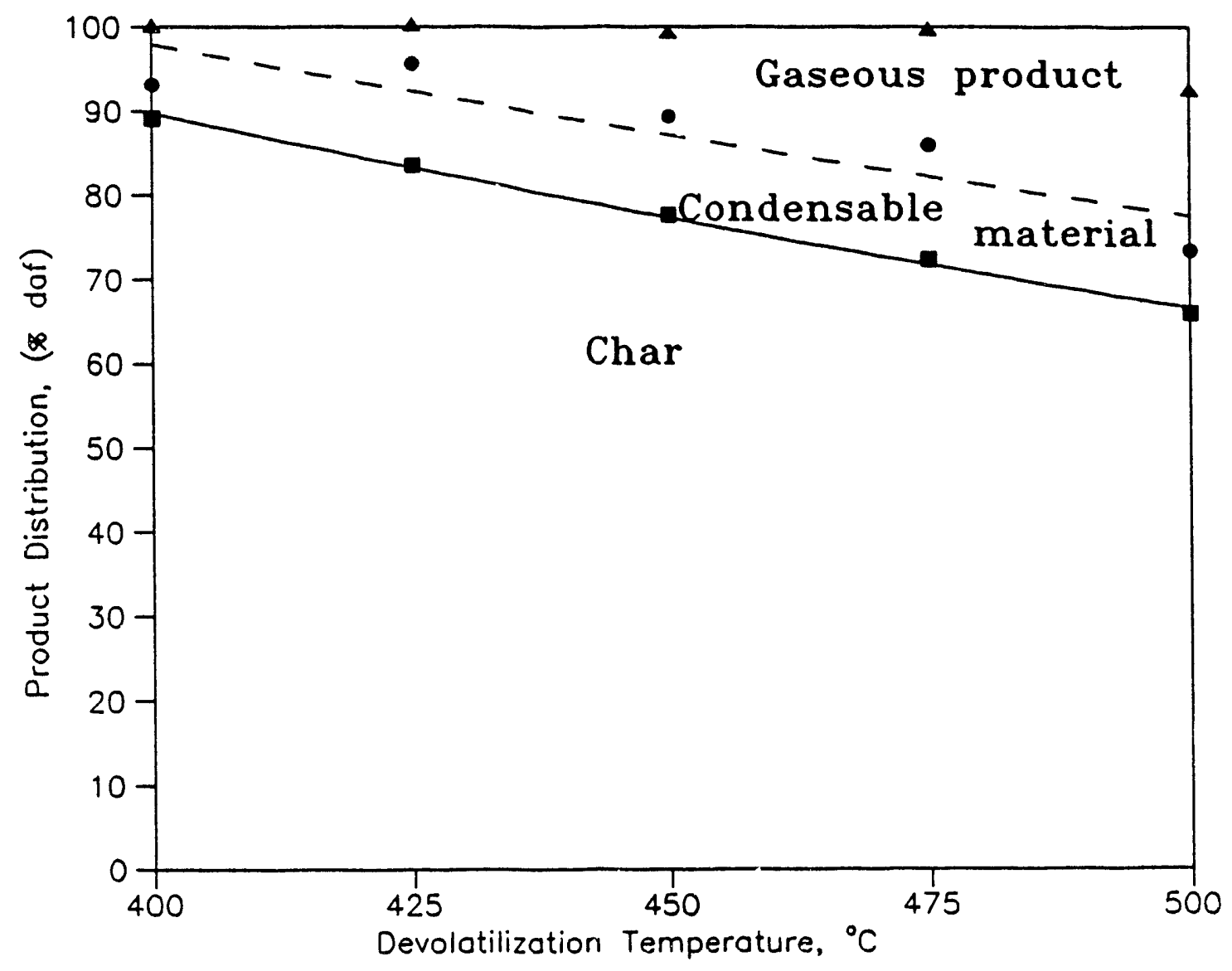

Figure 5.1.6 Residue composition of 200 grams coal at different pyrolysis temperatures with a residence time of 1.5 minutes 


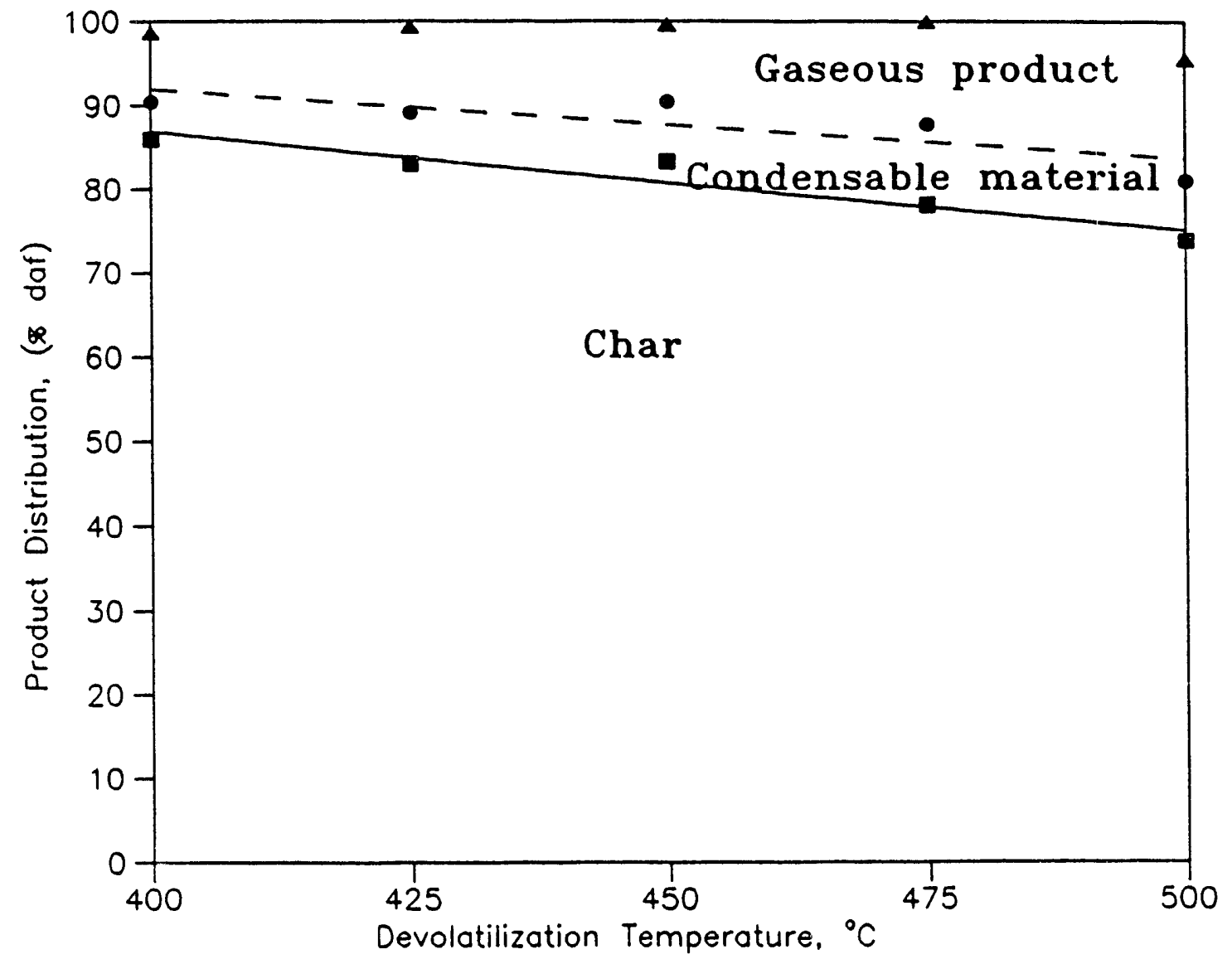

Figure 5.1.7 Residue composition of 300 grams coal at different pyrolysis temperatures with a residence time of 2.0 minutes 
Table 5.1.2 Nitrogen Content in Char at the First Phase Tests

\begin{tabular}{|c|c|c|}
\hline $\begin{array}{r}\text { Tepturature } \\
\left({ }^{\circ} \mathrm{C}\right)\end{array}$ & $\begin{array}{l}\text { Residence } \\
\text { time(min) }\end{array}$ & $\begin{array}{l}\text { Nitrogen in } \\
\text { char(\% daf) }\end{array}$ \\
\hline \multirow[t]{6}{*}{375} & 1.00 & 1.41 \\
\hline & 1.13 & 1.46 \\
\hline & 1.80 & 1.48 \\
\hline & 2.50 & 1.48 \\
\hline & 4.60 & 1.45 \\
\hline & 7.00 & 1.42 \\
\hline \multirow[t]{6}{*}{400} & 1.00 & 1.50 \\
\hline & 1.80 & 1.48 \\
\hline & 2.50 & 1.54 \\
\hline & 3.30 & 1.58 \\
\hline & 7.70 & 1.58 \\
\hline & 10.00 & 1.59 \\
\hline \multirow[t]{6}{*}{425} & 0.97 & 1.51 \\
\hline & 1.27 & 1.51 \\
\hline & 1.80 & 1.49 \\
\hline & 2.00 & 1.57 \\
\hline & 2.50 & 1.49 \\
\hline & 4.80 & 1.53 \\
\hline \multirow[t]{6}{*}{450} & 0.67 & 1.52 \\
\hline & 1.17 & 1.52 \\
\hline & 1.40 & 1.54 \\
\hline & 1.80 & .1 .52 \\
\hline & 2.55 & 1.61 \\
\hline & 4.60 & 1.62 \\
\hline
\end{tabular}


Table 5.1.3 Distribution of Pyrolysis Products Normalized to Parent Coal at the Second Phase Tests( d.a.f. )

\begin{tabular}{cccccc}
\hline Temperature & Char(\%) & $\operatorname{Tar}(\%)$ & Water(\%) & Gas(\%) \\
$\left({ }^{\circ} \mathrm{C}\right)$ & & & & &
\end{tabular}

300 grams of sample coal, at residence time 1.0 minute

$\begin{array}{lllll}400 & 95.38 & 0.46 & 0.69 & 2.86 \\ 425 & 85.43 & 1.22 & 3.64 & 5.52 \\ 450 & 87.28 & 3.60 & 5.27 & 3.57 \\ 475 & 76.79 & 3.97 & 3.62 & 9.86 \\ 500 & 80.83 & 5.11 & 3.69 & 11.74\end{array}$

200 grams of sample coal, at residence time 1.5 minutes

$\begin{array}{lllll}400 & 89.12 & 2.54 & 1.50 & 7.03 \\ 425 & 83.53 & 3.84 & 8.28 & 4.69 \\ 450 & 82.53 & 3.85 & 4.91 & 7.83 \\ 475 & 72.23 & 5.03 & 7.85 & 13.88 \\ 500 & 65.09 & 4.08 & 4.18 & 19.26\end{array}$

300 grams of sample cual, at residence time 2.0 minutes

$\begin{array}{rrrrr}400 & 86.00 & 1.50 & 2.96 & 8.22 \\ 425 & 83.07 & 2.77 & 3.28 & 10.23 \\ 450 & 83.23 & 3.14 & 4.08 & 9.15 \\ 475 & 78.08 & 7.08 & 2.06 & 12.24 \\ 500 & 73.75 & 3.25 & 3.95 & 14.64\end{array}$


Table 5.1.4 summarizes the nitrogen distribution in all the pyrolysis residue in the second phase testing results. The amount of nitrogen in tar is calculated by the nitrogen in tar and water because there are few light oil in water due to the incomplete separation of the condensable products. The amount of nitrogen contained in gaseous products was determined by the mass balance of the nitrogen in parent coal, char, tar, and water. These results indicate that very little volatile nitrogen is evolved at temperatures below $450^{\circ} \mathrm{C}$. The nitrogen amount of volatile pyrolysis residue(tar and gases) and the total yield during each temperature testing were shown in the following illustration from Figures 5.1.8 to 5.1.13. Nitrogen content in volatile residue has no noticeable change during temperatures from 400 to $500^{\circ} \mathrm{C}$. As the amount of volatile residue increases with the increasing pyrolysis temperature, the evolution of nitrogen containing species increase. The tar nitrogen yield was lower(Figures 5.1 .10 and 5.1 .12 ) at $500^{\circ} \mathrm{C}$ of 1.5 and 2.0 minutes pyrolysis tests where the yield of gaseous nitrogen was higher(Figures 5.1.11 and 5.1.13). These results indicate that some of the nitrogen in gaseous products of mild pyrolysis might be postulated to be secondary decomposition of tar rather than primary products of coal decomposition at $500^{\circ} \mathrm{C}$. The gaseous nitrogen in 1.0 residence time pyrolysis had a big fluctuation may be partly due to the error of residue weight measurements. Again, devolatilization dominates the denitrification in the second phase tests(Figures 5.1.14 5.1.16). The linear relationship between devolatilization and denitrification were presented on Figures 5.1.17 and 5.1.18. The results indicate that nitrogen content in volatile residue of coal pyrolysis might be' fix' and is the only nitrogen can be removed by this process.

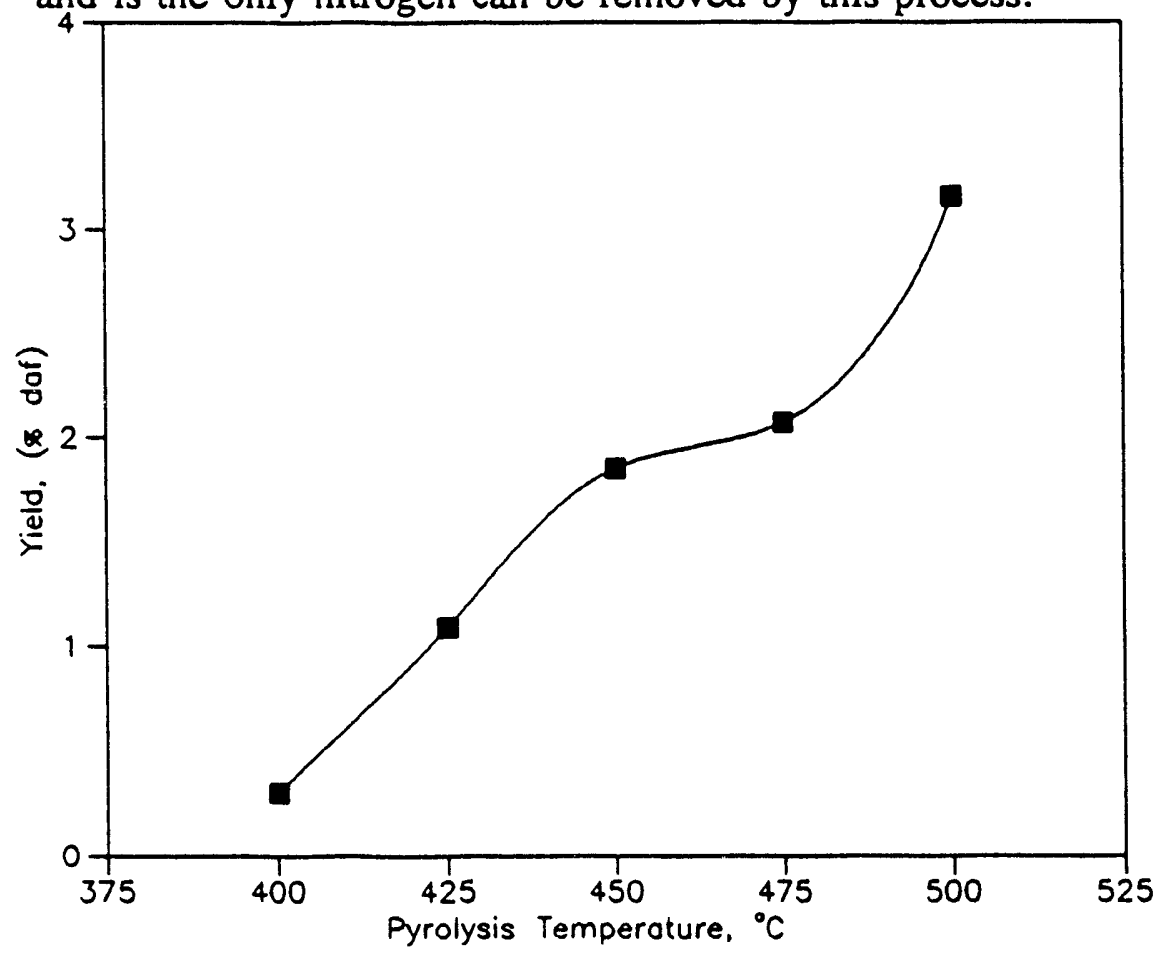

Figure 5.1.8 Tar nitrogen as a percent of total nitrogen in 300 grams coal pyrolyzed at different temperatures with a residence time of 1.0 minute 


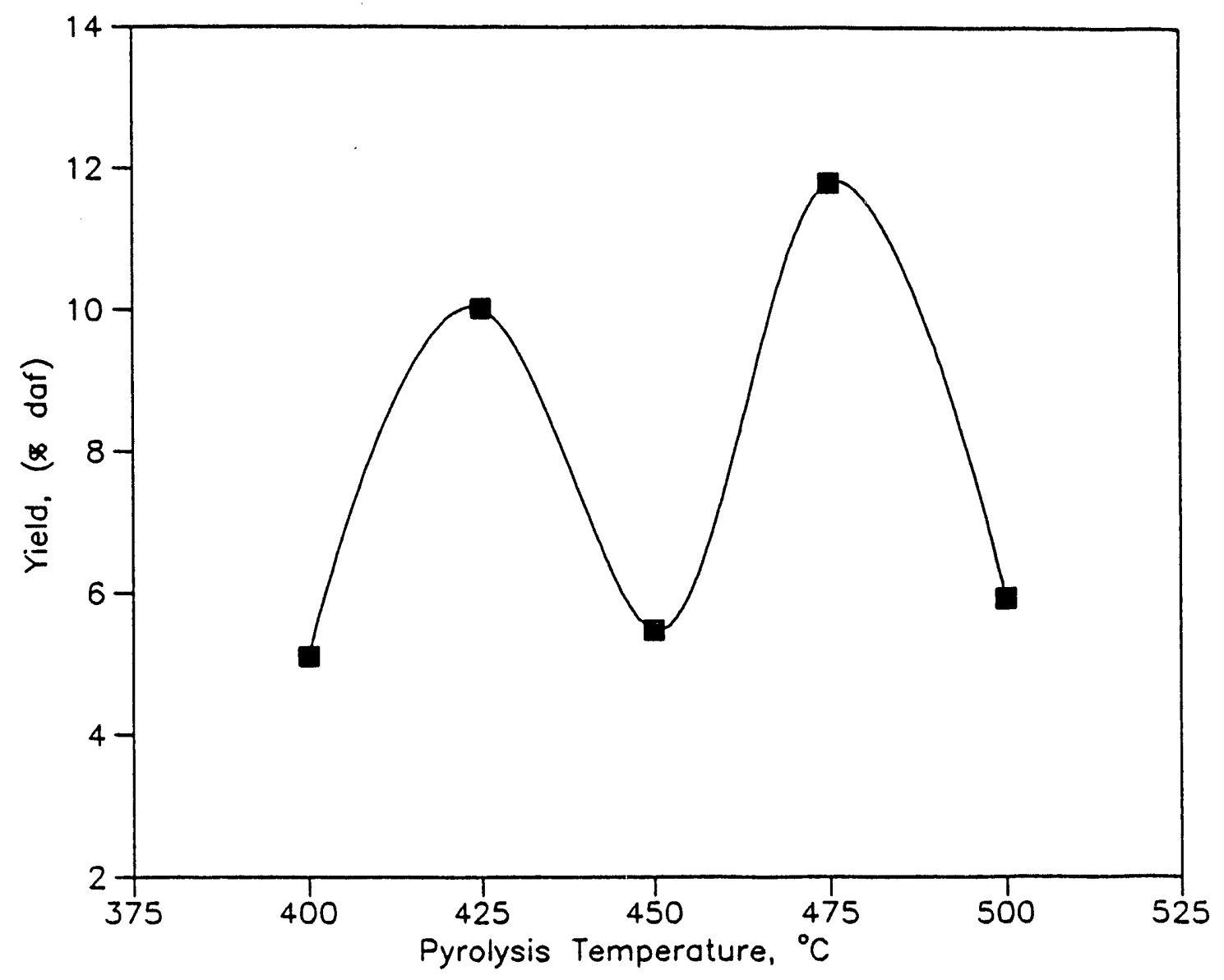

Figure 5.1.9 Gaseous nitrogen as a percent of total nitrogen in 300 grams coal at different temperatures with a residence time of 1.0 minute 


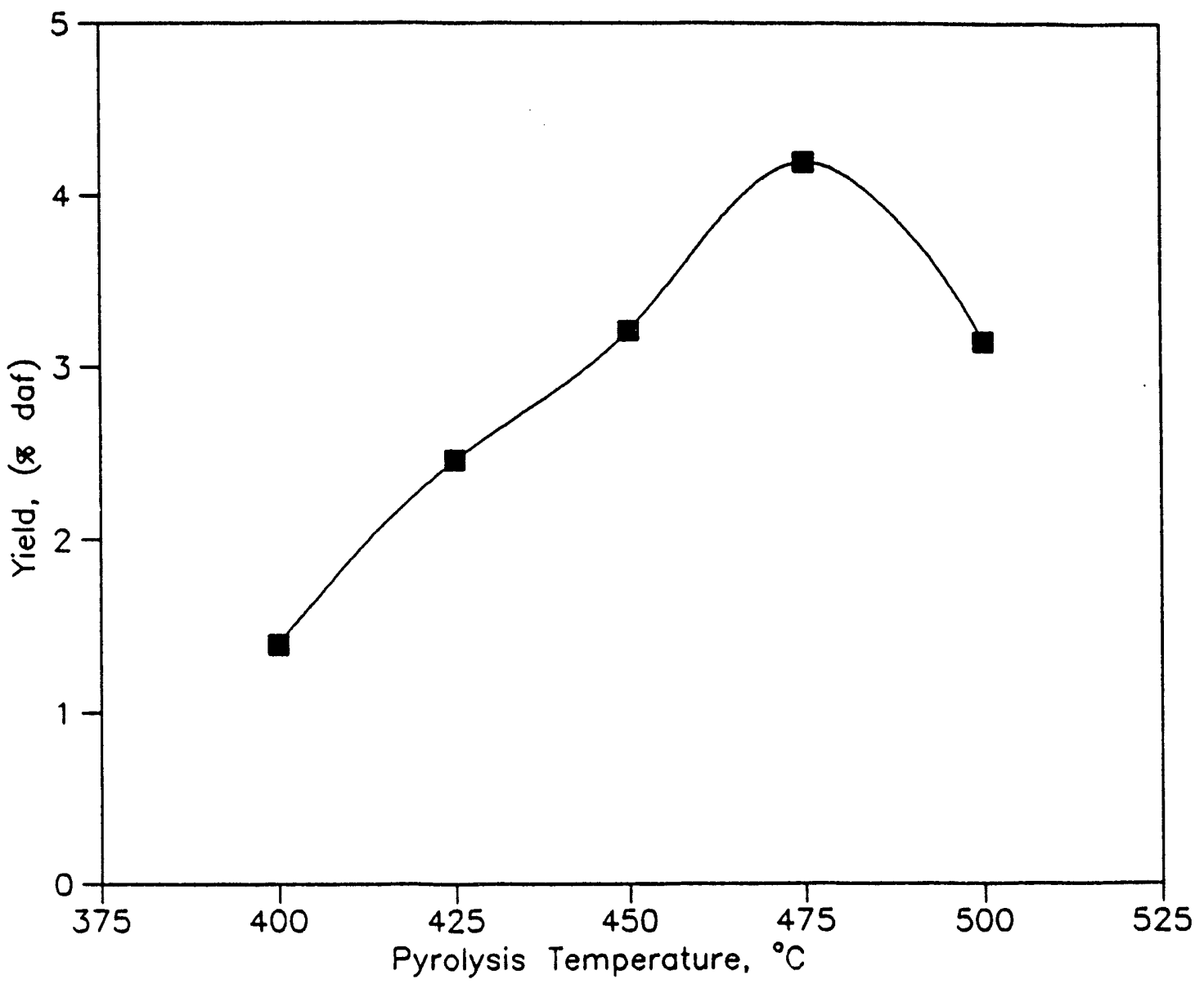

Figure 5.1.10 Tar nitrogen as a percent of total nitrogen in 200 grams coal pyrolyzed at different temperatures with a residence time of 1.5 minutes 


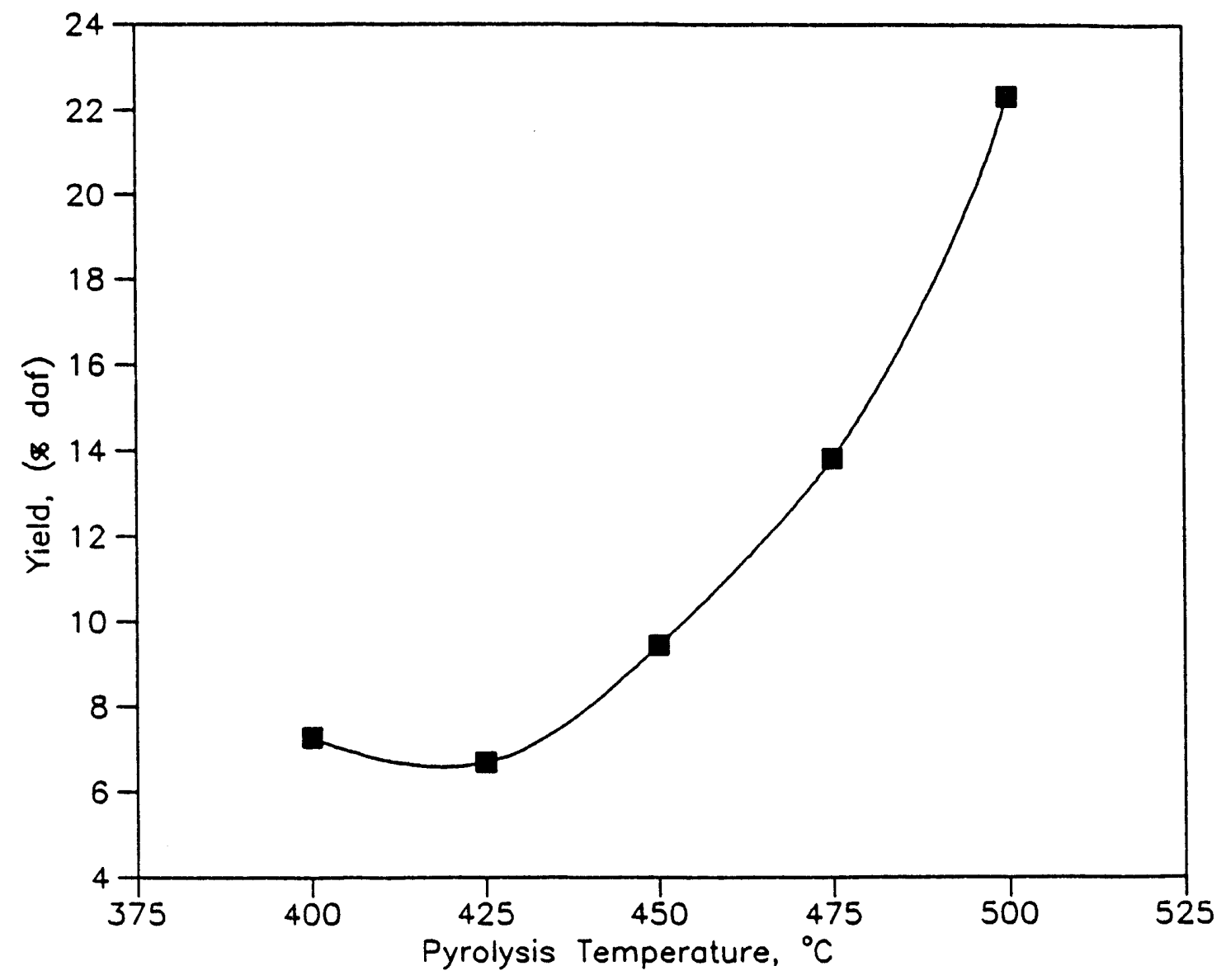

Figure 5.1.11 Gaseous nitrogen as a percent of total nitrogen in 200 grams coal pyrolyzed at different temperatures with a residence time of 1.5 minutes 


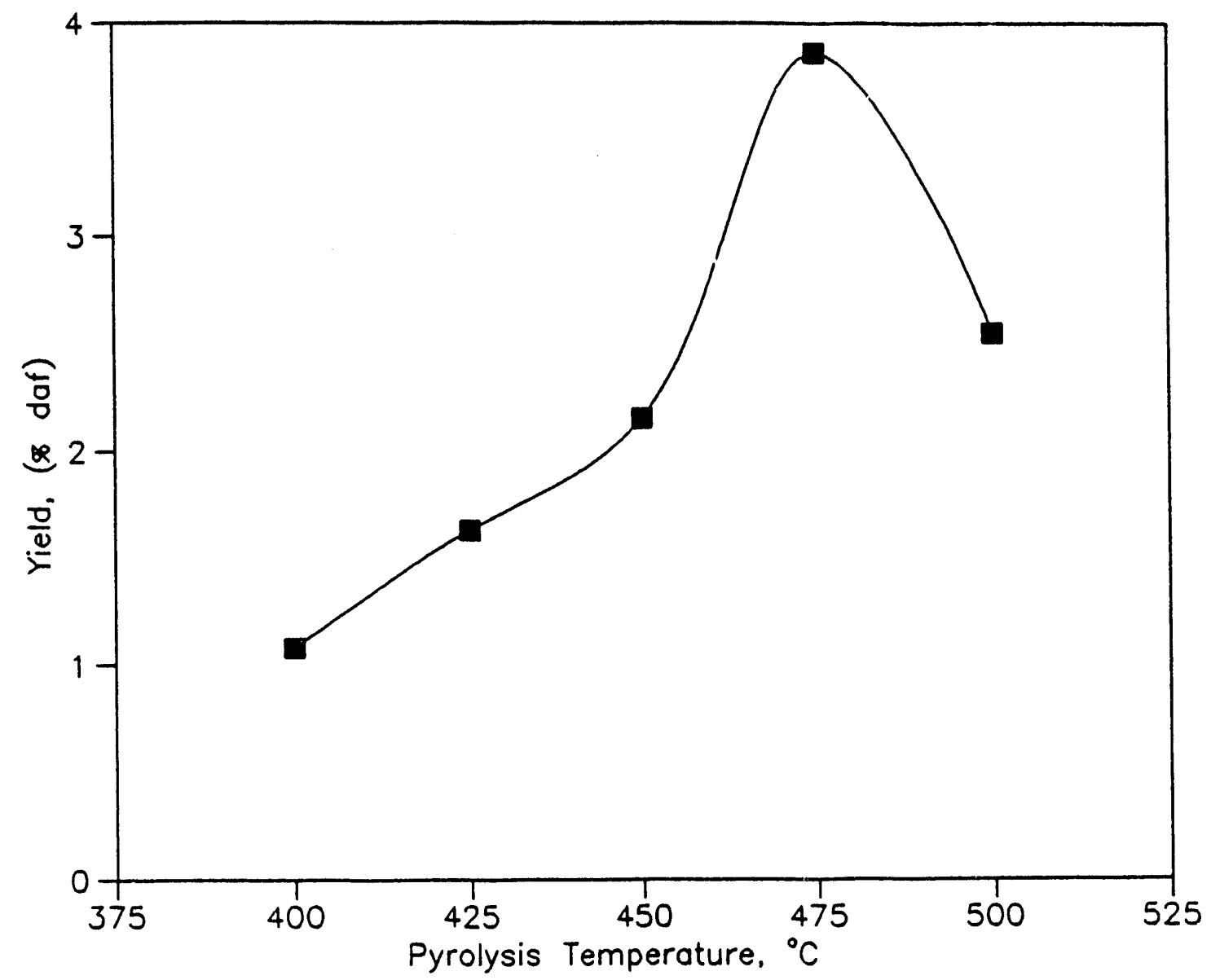

Figure 5.1.12 Tar nitrogen as a percent of total nitrogen in 300 grams coal pyrolyzed at different temperatures with a residence time of 2.0 minutes 


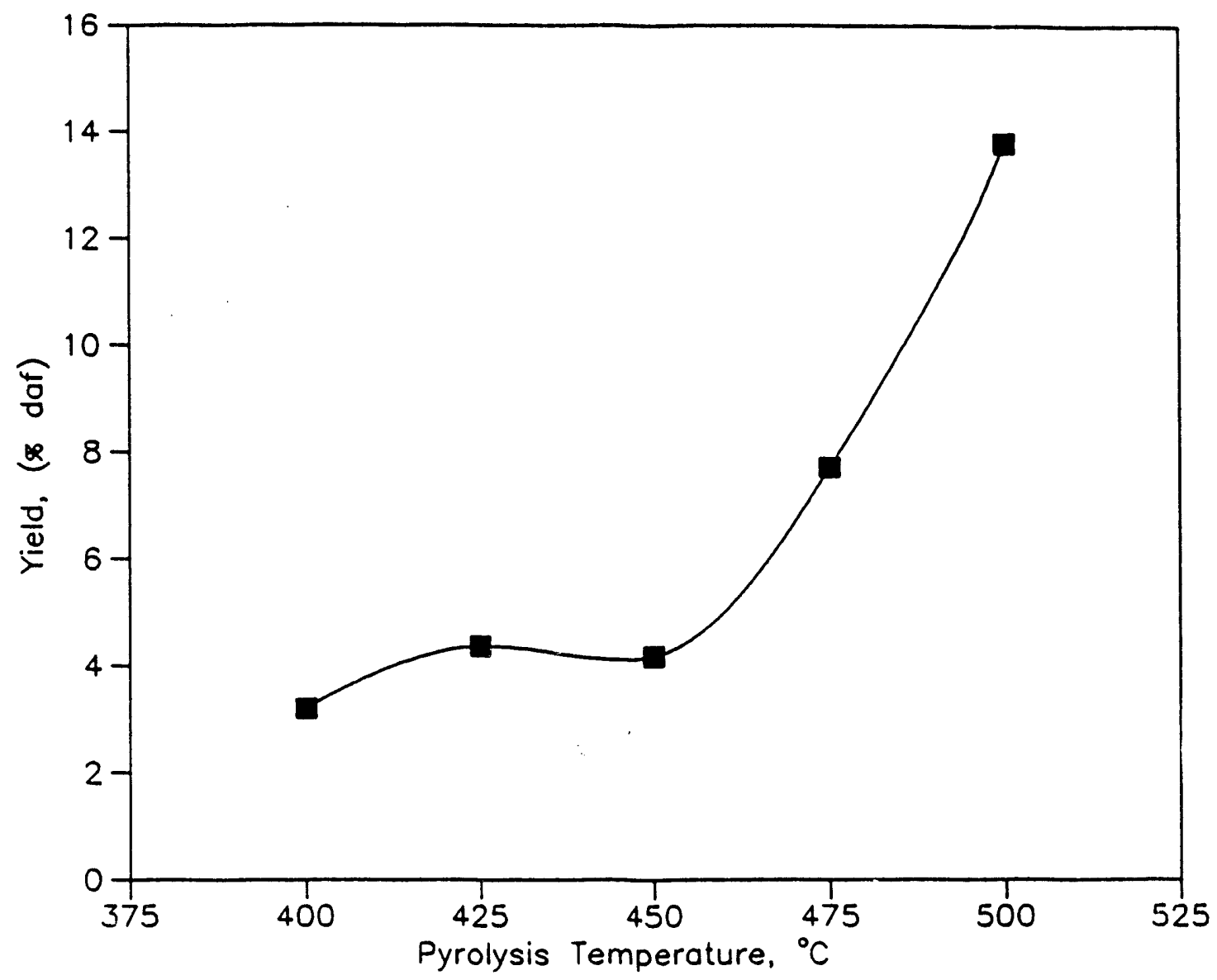

Figure 5.1.13 Gaseous nitrogen as a percent of total nitrogen in 300 grams coal pyrolyzed at different temperatures with a residence time of 2.0 minutes 


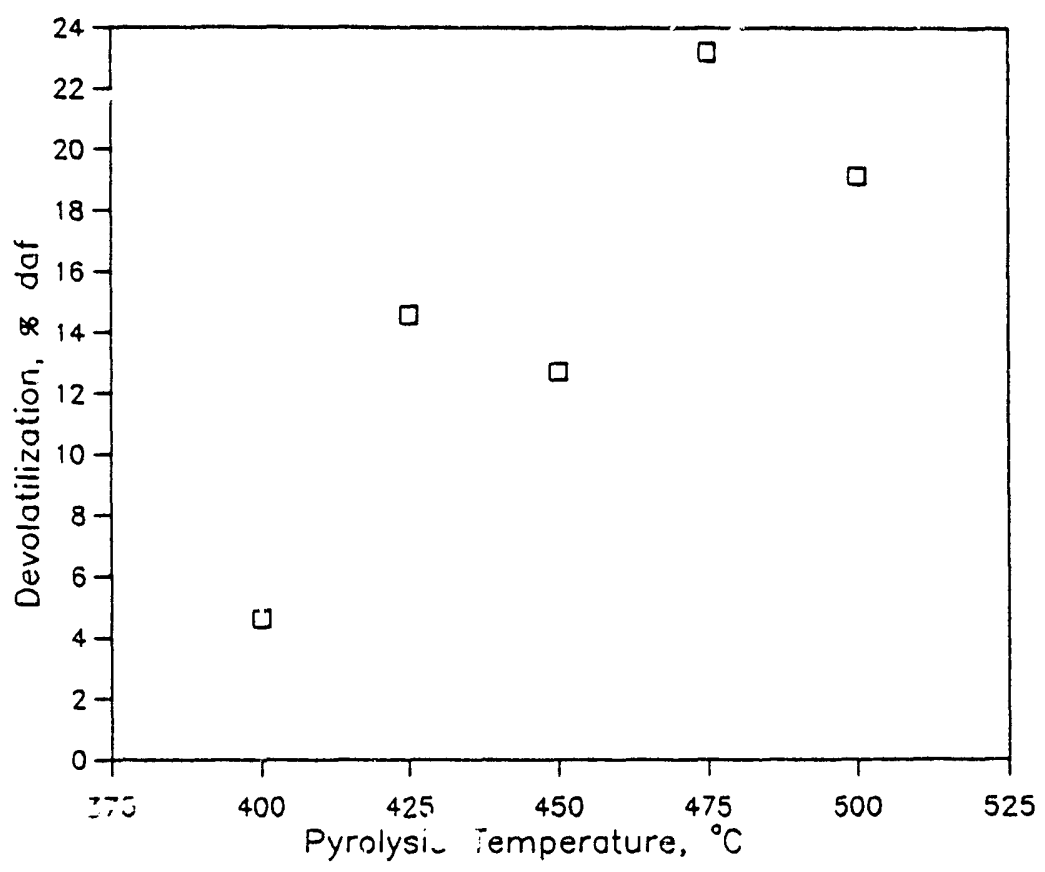

Figure 5.1.14(a) Devolatilization at different temperatures with a residence time of 1.0 minute in the second phase

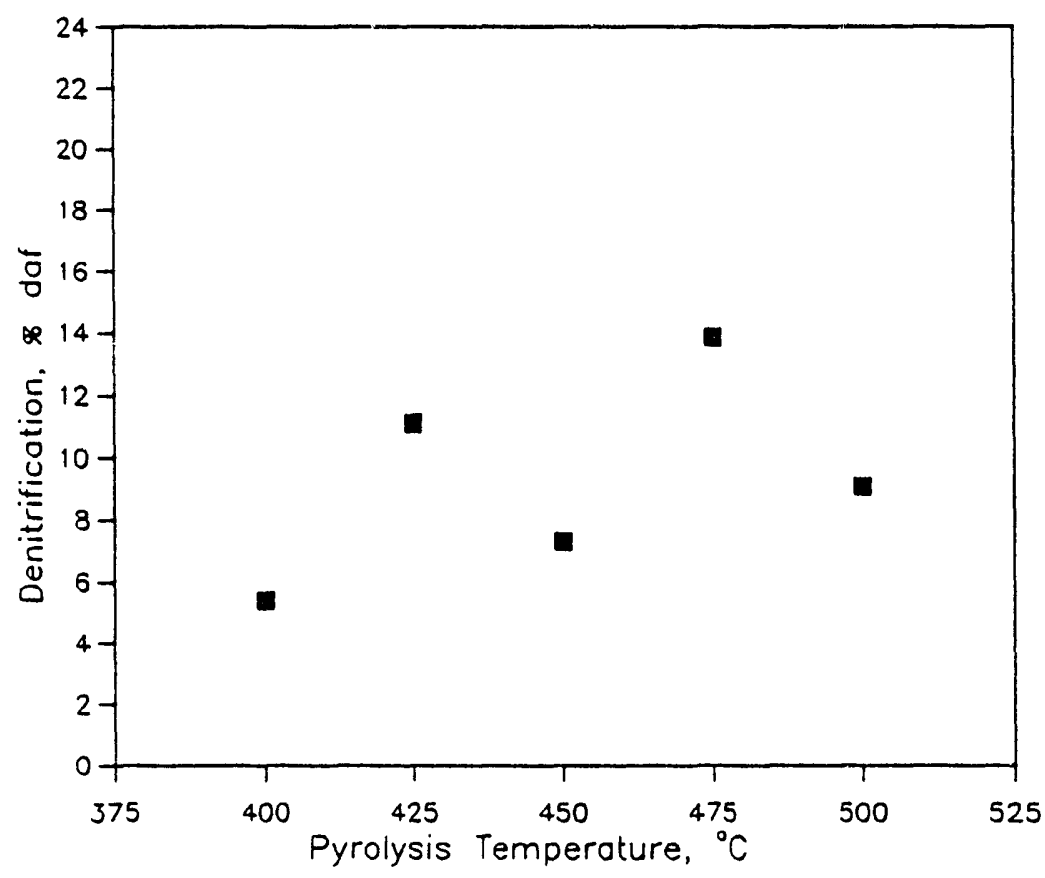

Figure 5.1.14(b) Denitrification at different temperatures with a residence time of 1.0 minute in the second phase 


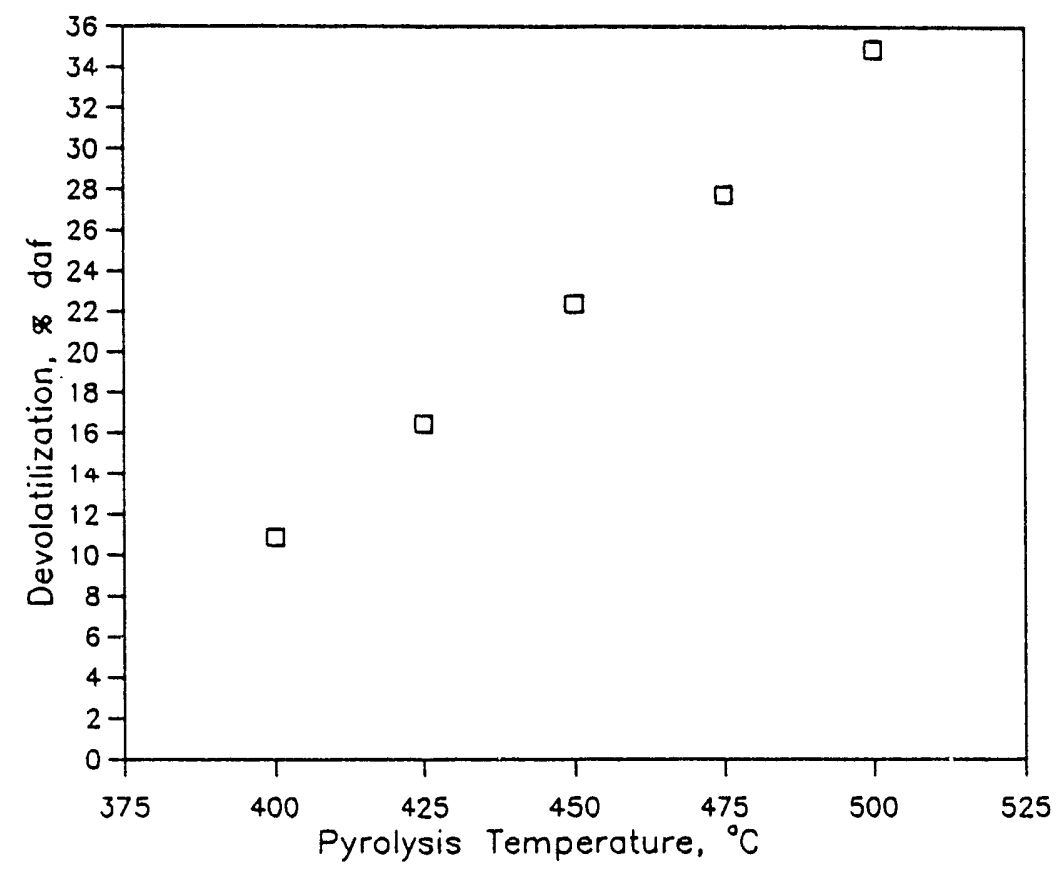

Figure 5.1.15(a) Devolatilization at different temperatures with a residence time of 1.5 minutes in the second phase

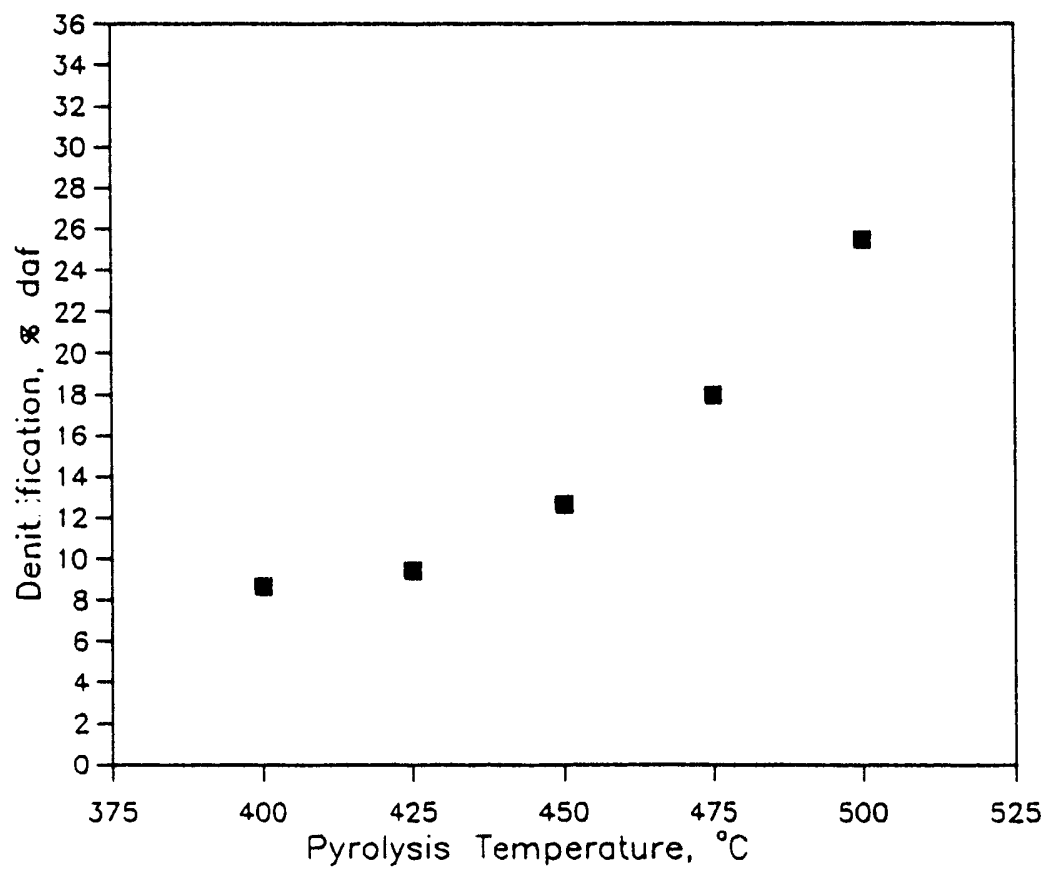

Figure 5.1.15(b) Denitrification at different temperatures with a residence time of 1.5 minutes in the second phase 


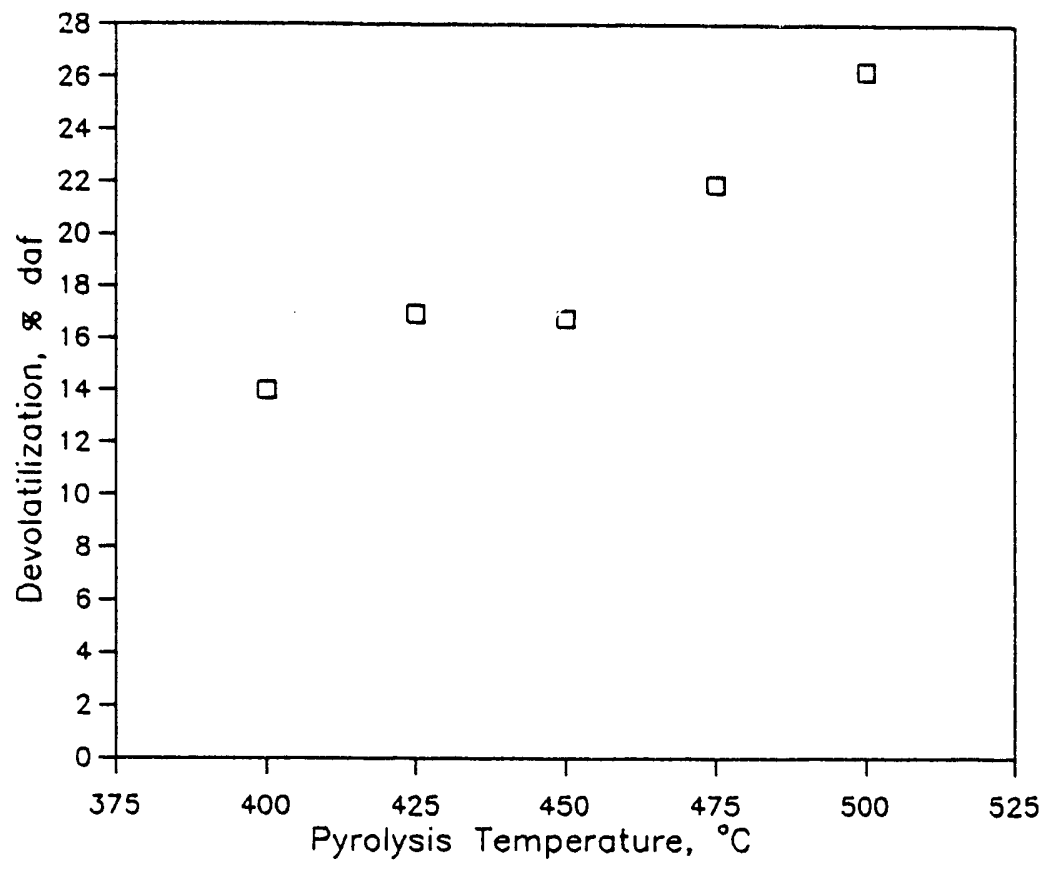

Figure 5.1.16(a) Devolatilization at different temperatures with a residence time of 2.0 minutes in the second phase

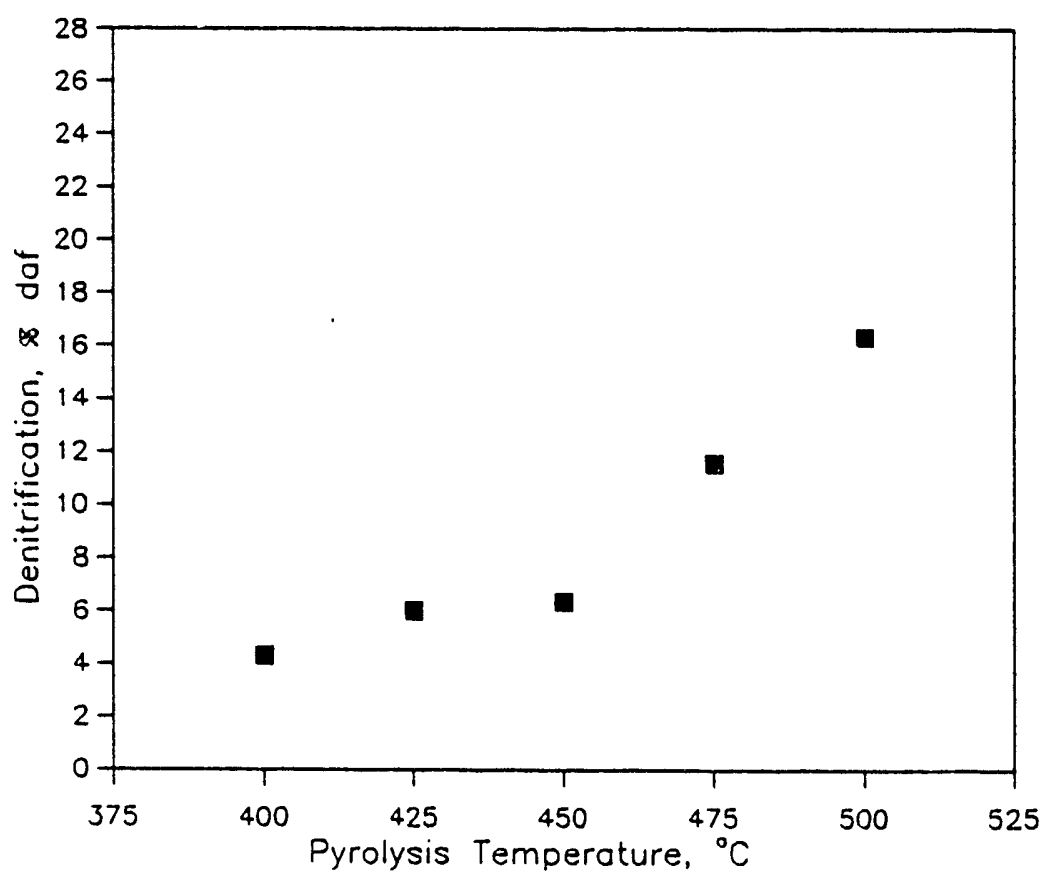

Figure 5.1.16(b) Denitrification at different temperatures with a residence time of 2.0 minutes in the second phase 


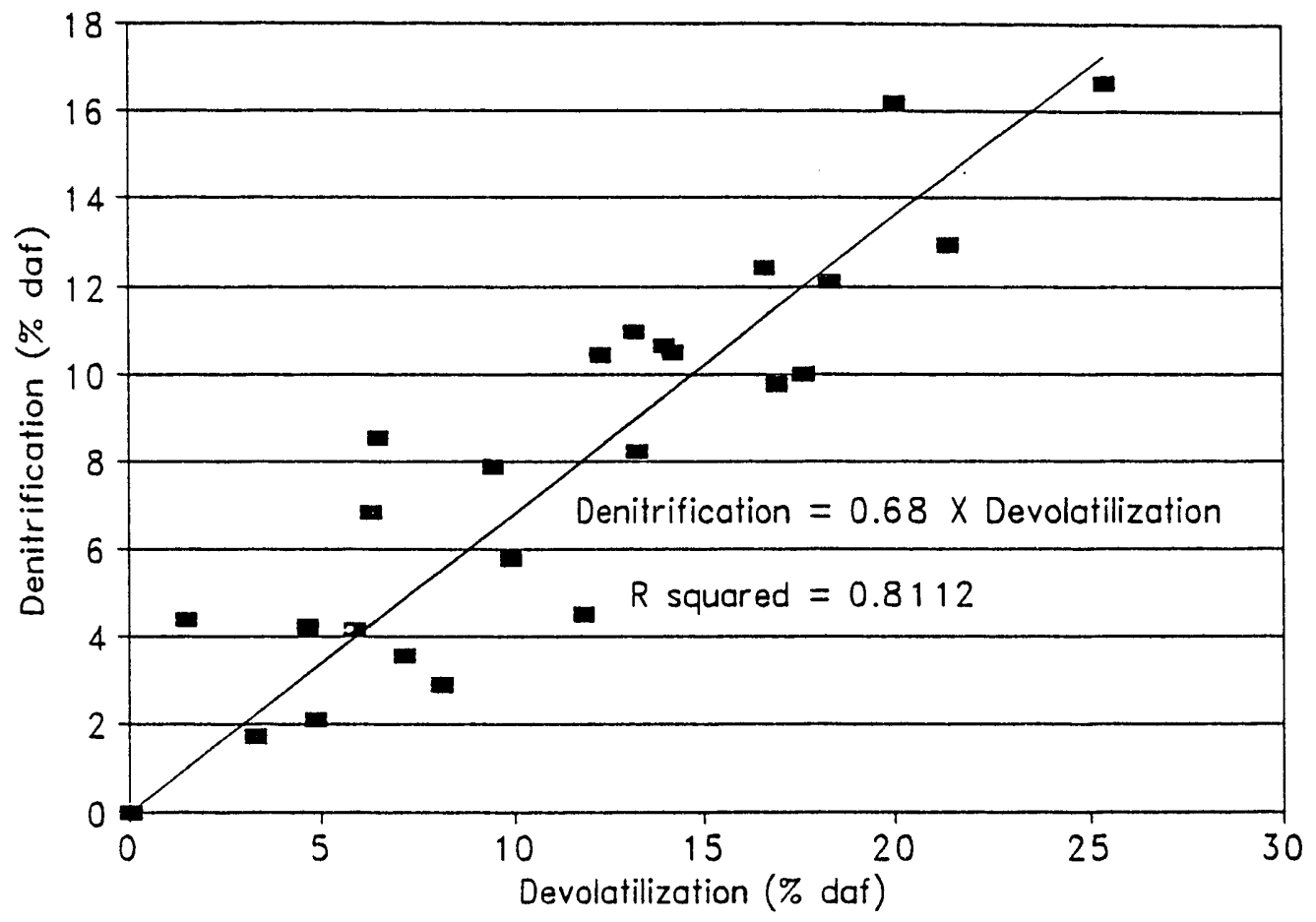

Figure 5.1.17 Regression of denitrification on devolatilization in the first phase pyrolysis tests 


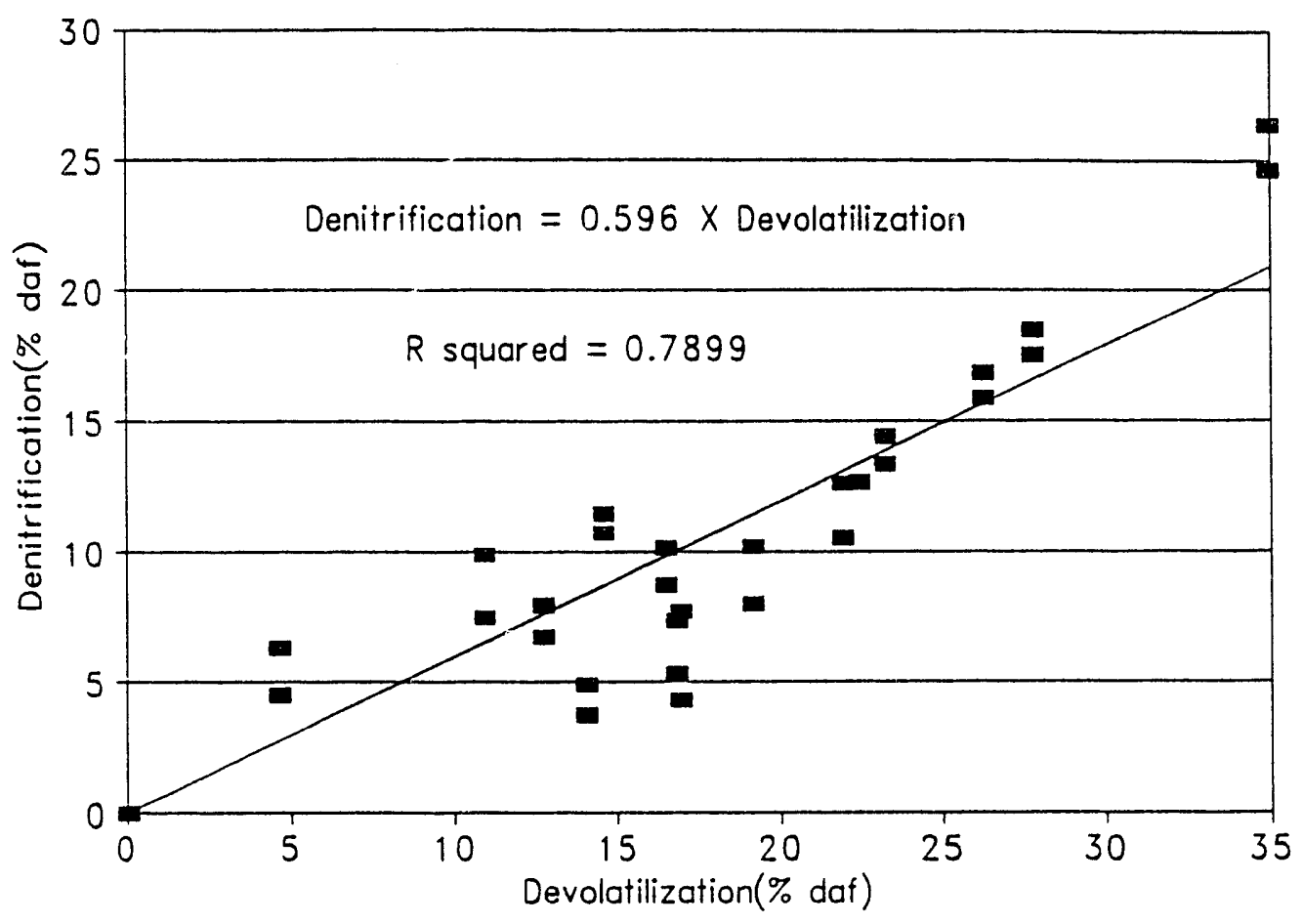

Figure 5.1.18 Regression of denitrification on devolatilization in the second phase pyrolysis tests 
Table 5.1.4 Nitrogen Distribution of Pyrolysis Residue

Temperature
$\left({ }^{\circ} \mathrm{C}\right)$

300 grams of sample coal pyrolyzed at residence time 1.0 minute

$\begin{array}{rrrr}400 & 94.61 & 0.30 & 5.10 \\ 425 & 88.90 & 1.09 & 10.01 \\ 450 & 92.68 & 1.85 & 5.47 \\ 475 & 86.14 & 2.07 & 11.80 \\ 500 & 90.91 & 3.16 & 5.92\end{array}$

200 grams of sample coal pyrolyzed at residence time 1.5 minutes

$\begin{array}{llll}400 & 91.34 & 1.39 & 7.28 \\ 425 & 90.58 & 2.46 & 6.96 \\ 450 & 89.83 & 2.36 & 7.81 \\ 475 & 82.01 & 4.19 & 13.80 \\ 500 & 74.53 & 3.14 & 22.33\end{array}$

300 grams of sample coal pyrolyzed at residence time 2.0 minutes

$\begin{array}{llll}400 & 95.73 & 1.08 & 3.20 \\ 425 & 94.01 & 1.63 & 4.36 \\ 450 & 93.67 & 2.15 & 4.17 \\ 475 & 88.44 & 3.86 & 7.70 \\ 500 & 83.67 & 2.54 & 13.79\end{array}$




\subsection{Ash Tracer as Devolatilization}

Since the overall kinetics of this mild pyrolysis reaction were measured from the weight loss as a devolatilization rate, the results were questionable when fluctuations occurred during the pyrolysis testing period. The analysis of ash content in both the char and its parent coal was undertaken in order to examine the representative weight loss when using ash as a tracer material. Equation 5.2.1 below assumes that mineral matter content in the coal is not transformed while passing through the feed tube.

$$
\operatorname{DeVol}(\% \text { daf })=\left(1-\frac{A s h_{\text {coal }}}{A s h_{\text {char }}}\right) 100
$$

where $A s h_{\text {coal }}$ and $A s h_{\text {char }}$ are the ash contents of coal and char, respectively, on a dry, ash-free basis. A comparison with the devolatilization calculated from weight loss using ash as a tracer is presented in Figures 5.2.1, 5.2.2, and 5.2.3 at different residence time.

An interpretation of the results indicates that the representation of devolatilization by weight loss displays an overweight of char in most of the tests in the second phase. By back calculation, a $15 \%$ error of weight loss compared to a $10 \%$ error of mass balance indicates that the pyrolysis had a systematic problem. Char captured moisture and oxygen in quench tank and in the air before it was weighed. In the meantime, condensable product like tar was found to deposit in the tube mounted on the quench tank and some sampling tube. The amount of volatile is underweight.

\subsection{The Effects of Pyrolysis Temperature}

Temperature is the most important variable affecting the composition of pyrolysis products from a coal. The role of temperature includes two primary effects, one on the decomposition of the coal and the other on the secondary reactions of volatiles. In the absence of secondary reactions in mild conditions, the yield of a given volatile component increases with increasing temperature. The effects of temperature are clearly coupled with those of time, but the residence time played a relatively secondary role if the rates of reactions were chemically controlled. The following discussion will be focused on the kinetics of devolatilization and denitrification in this study. 


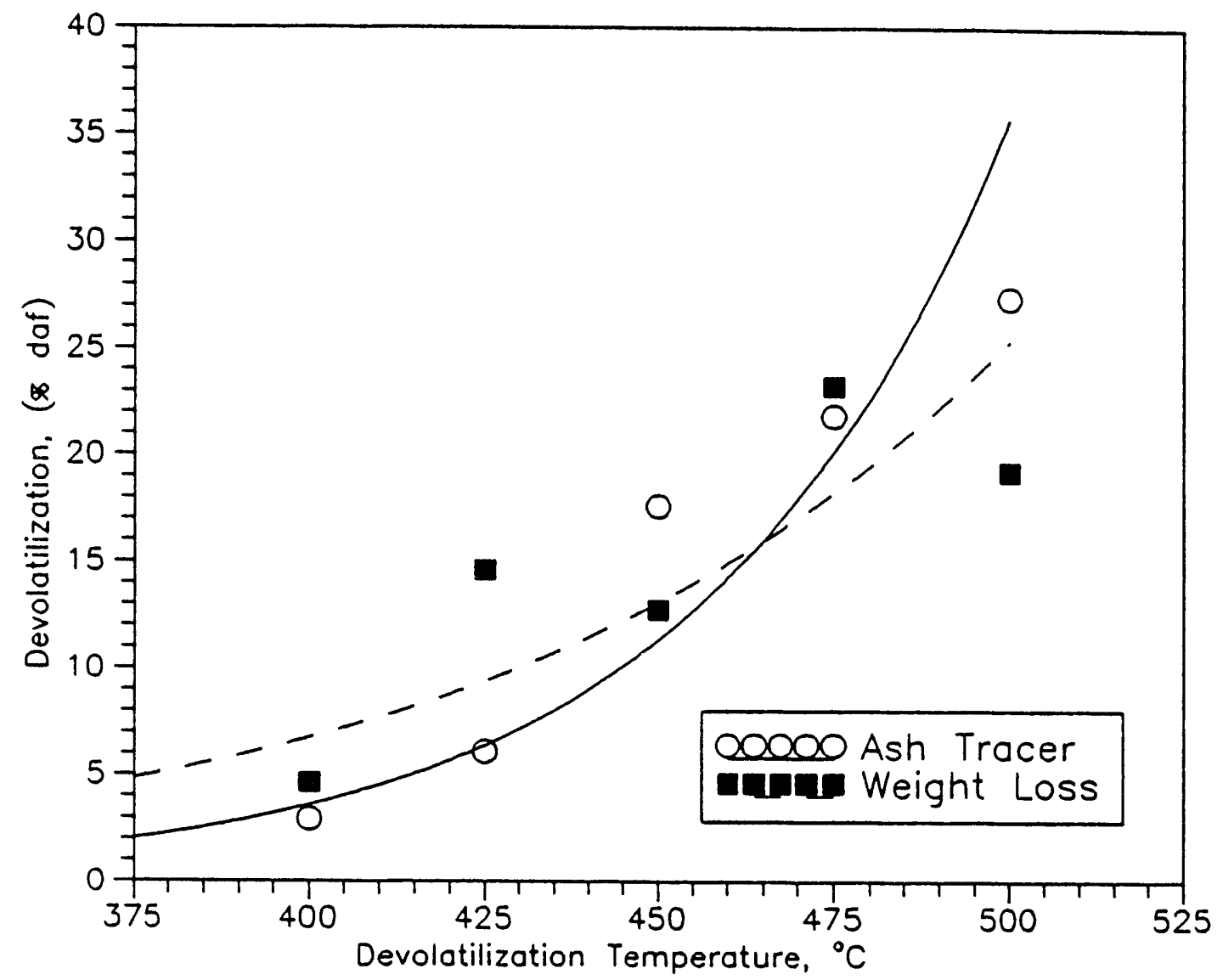

Figure 5.2.1 Devolatilization expressed by weight loss and by ash tracer at 1.0 minute residence time pyrolysis tests in the second phase 


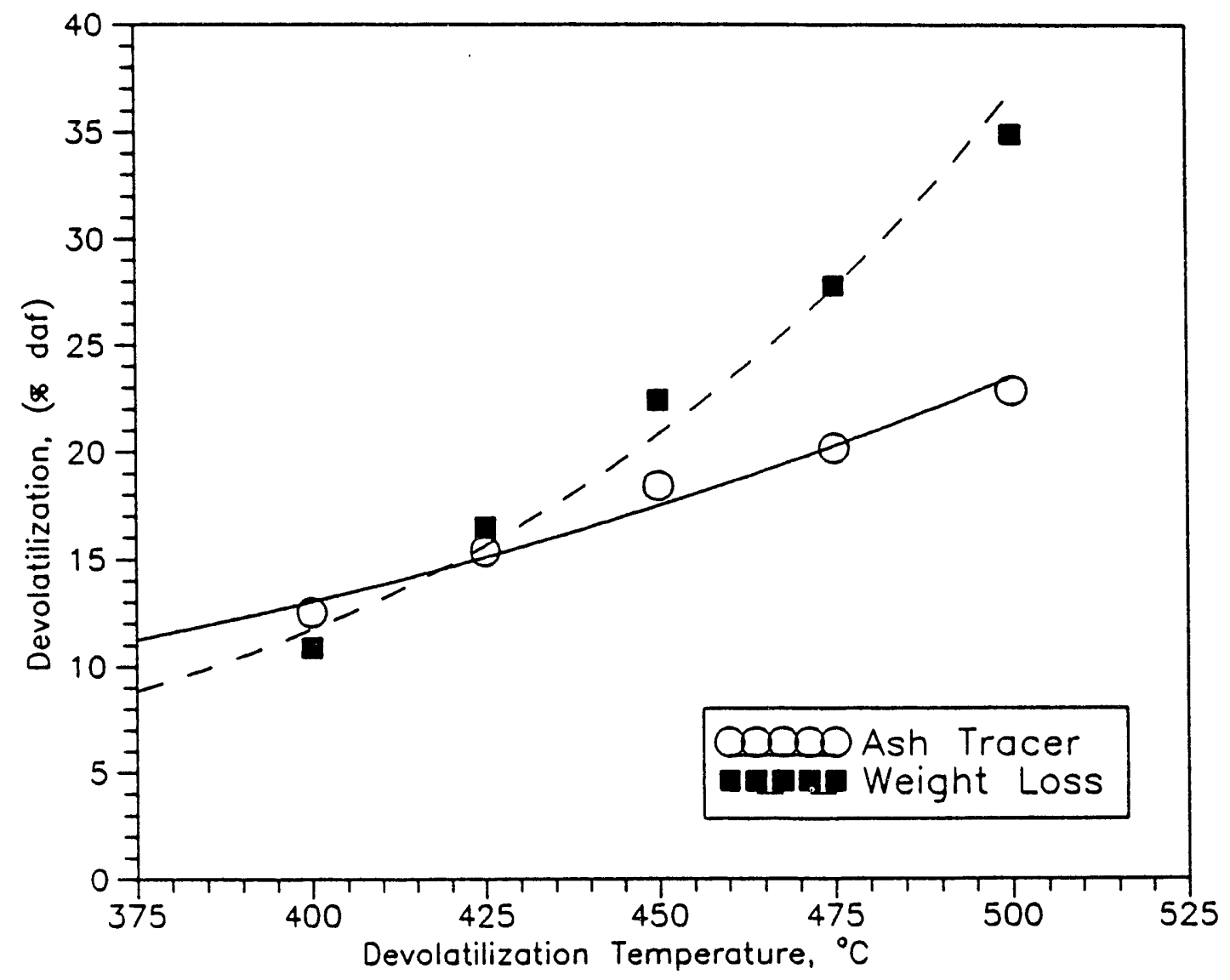

Figure 5.2.2 Devolatilization expressed by weight loss and by ash tracer at 1.5 minutes residence time pyrolysis tests in the second phase 


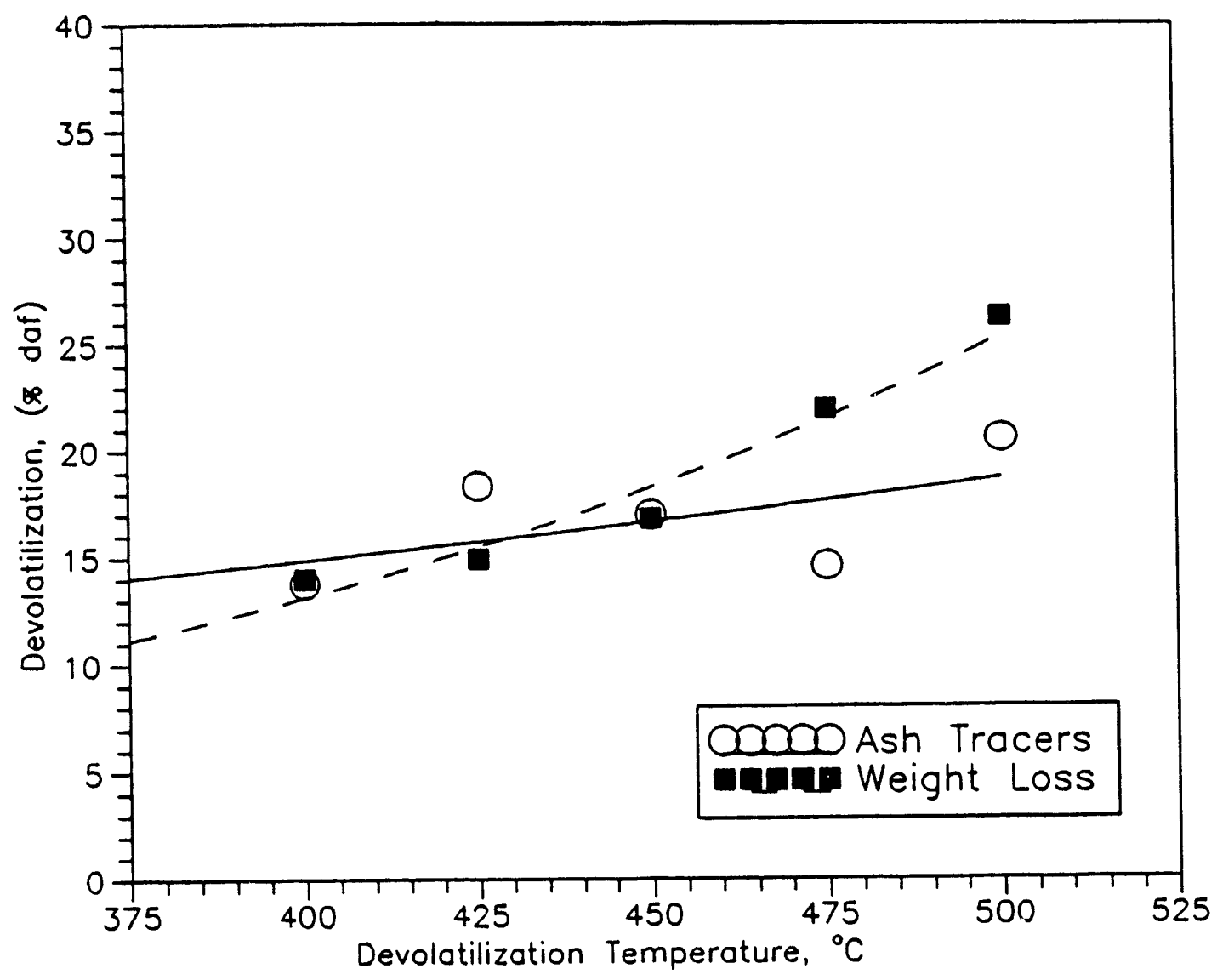

Figure 5.2.3 Devolatilization expressed by weight loss and by ash tracer at 2.0 minutes residence time pyrolysis tests in the second phase 


\subsection{Kinetics of Devolatilization and Denitrification}

Since the devolatilization is accomplished at a constant temperature and the evolution of each product is assumed to be an independent process, the expression for $W_{i}$ in equation 2.3.2 can be integrated to yield

$$
W_{i}=W_{o}\left(1-\exp \left(-k_{i} t\right)\right)
$$

The rate parameter $A$ and the activation energy $E_{i}$ in equation 2.3.2 are determined by plotting with experimental data where $\mathrm{T}$ is the temperature in ${ }^{\circ} \mathrm{K}$ and the universal gas constant $R$ is equal to $8.314 \mathrm{KJ} \mathrm{g} \mathrm{mol}^{-1}{ }^{\circ} \mathrm{K}^{-1}$ in this determination. The rate constant $k_{i}$ were determined from the plot of data from each pyrolysis run. The expression of the devolatilization and denitrification rate constant $k_{i}$ are illustrated in Figures 5.4.1(a)(b) and 5.4.2(a)(b). Although there is a variation in the reported rate constant of between two and four orders of magnitude due to the effects of the different type of coal type, the heating rate, mass transfer rate,etc., the pyrolysis conditions in both phases were conducted in a very similar process that the possible variables introduced in deriving kinetic rates could be eliminated. The coal has melted and the volatile species have formed bubble cells structure during pyrolysis. By the intermediate heating rate, the cells can coalesce and coal particles can swell somewhat before rupture. The rate constant of devolatilization in the first phase is faster than that of in the second phase tests. This result indicates that the steel balls employed in the second phase provided much more paths for the evolution of tar and gas to accelerate the rate of reaction. The same phenomena occurred to denitrification. The above discussion suggests that the major factors influencing the rate for reactions of devolatilization are the rate of heat transfer to two particles and the rate of mass transfer of the pyrolysis products. These effects are apparently significant at high temperatures.

The activation energy of devolatilization and denitrification plotting by Arrhenius form of each phase testing are shown on Figures 5.4.3 and 5.4.4. The steel balls not only expedited the rate of pyrolysis reaction in the second phase but also reduced coal particle from agglomerating. Much more volatile species escaped to surface of coal particle and evolved during pyrolysis in the second phase. The activation energy of devolatilization in the second phase was less than that of in the first phase because the volatile species evolved with less resistance in the second phase. Not like devolatilization, the activation energy of denitrification in the second phase was greater than that of in the first phase(Figure 5.4.4). As mentioned in Section 5.1, nitrogen evolution in the second phase tests might involve the secondary decomposition of tar at higher pyrolysis temperatures. Much more energy are required to break chemical bonds to release nitrogen. The kinetics definitely support the results of denitrification. 


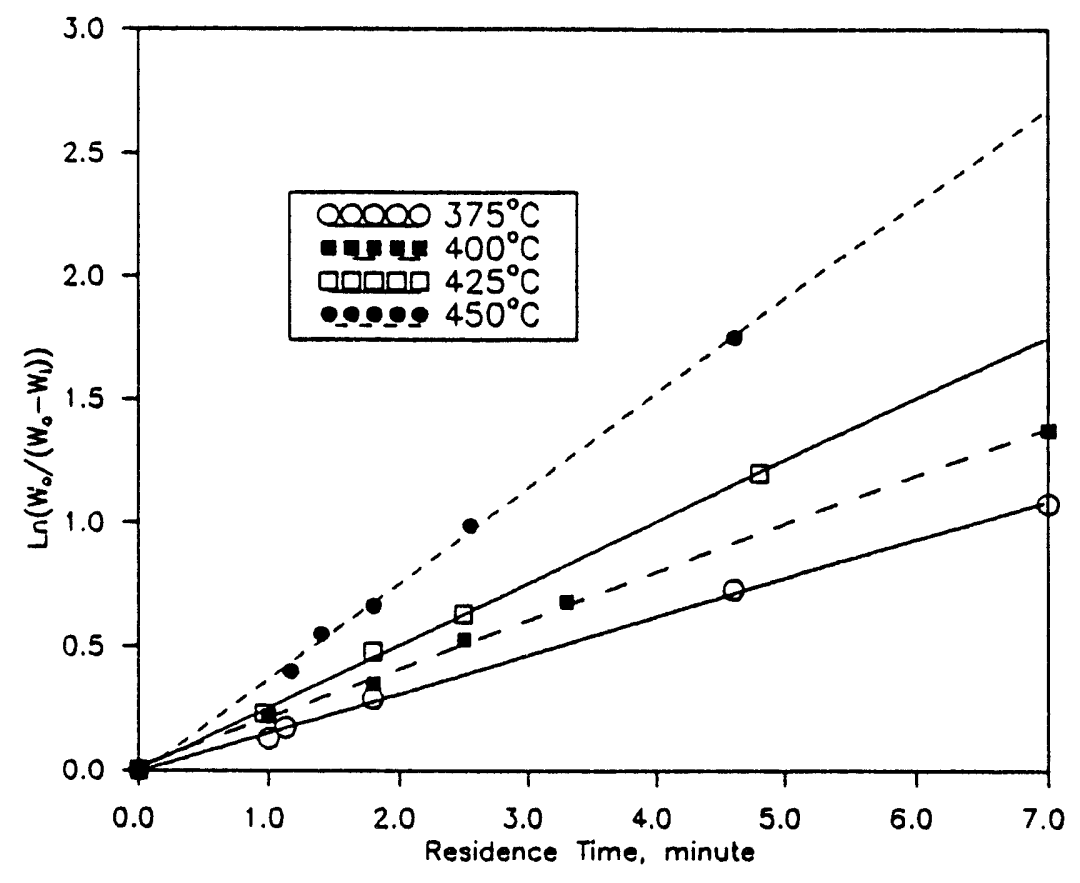

Figure 5.4.1(a) Devolatilization rate constant for the pyrolysis tests in the first phase

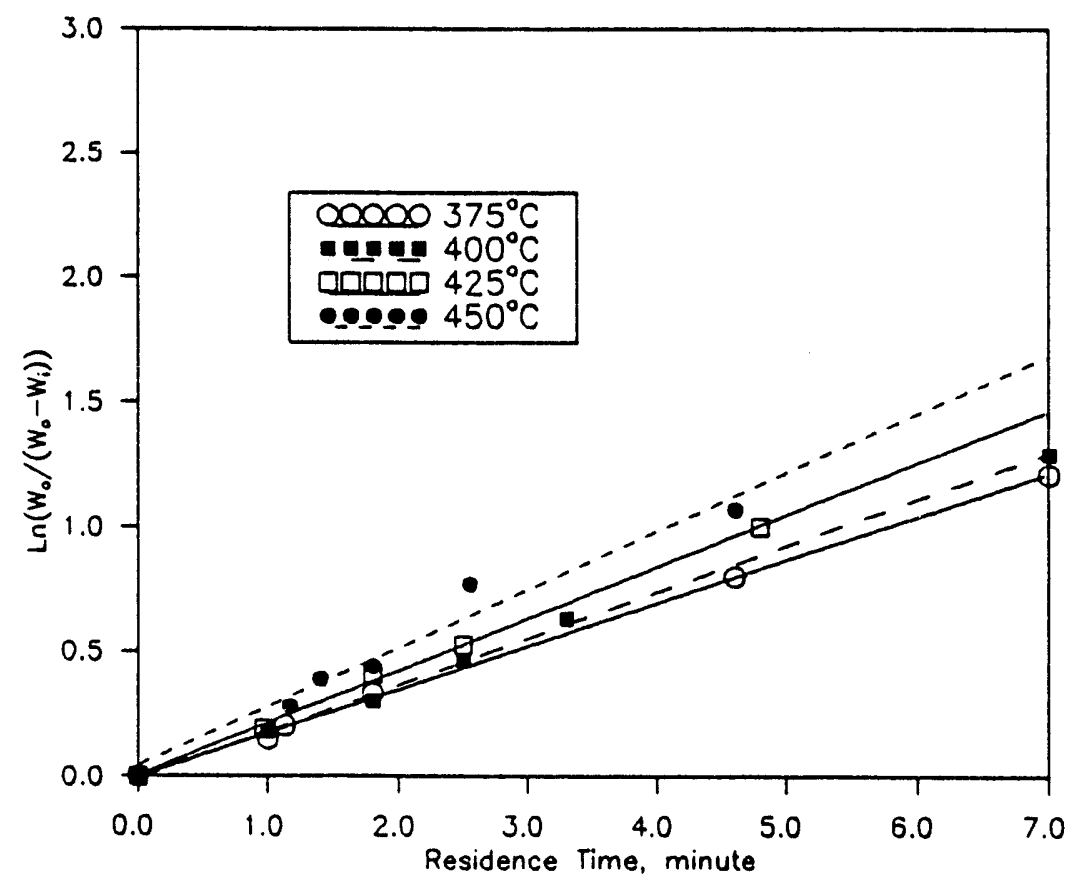

Figure 5.4.1(b) Denitrification rate constant for the pyrolysis tests in the first phase 


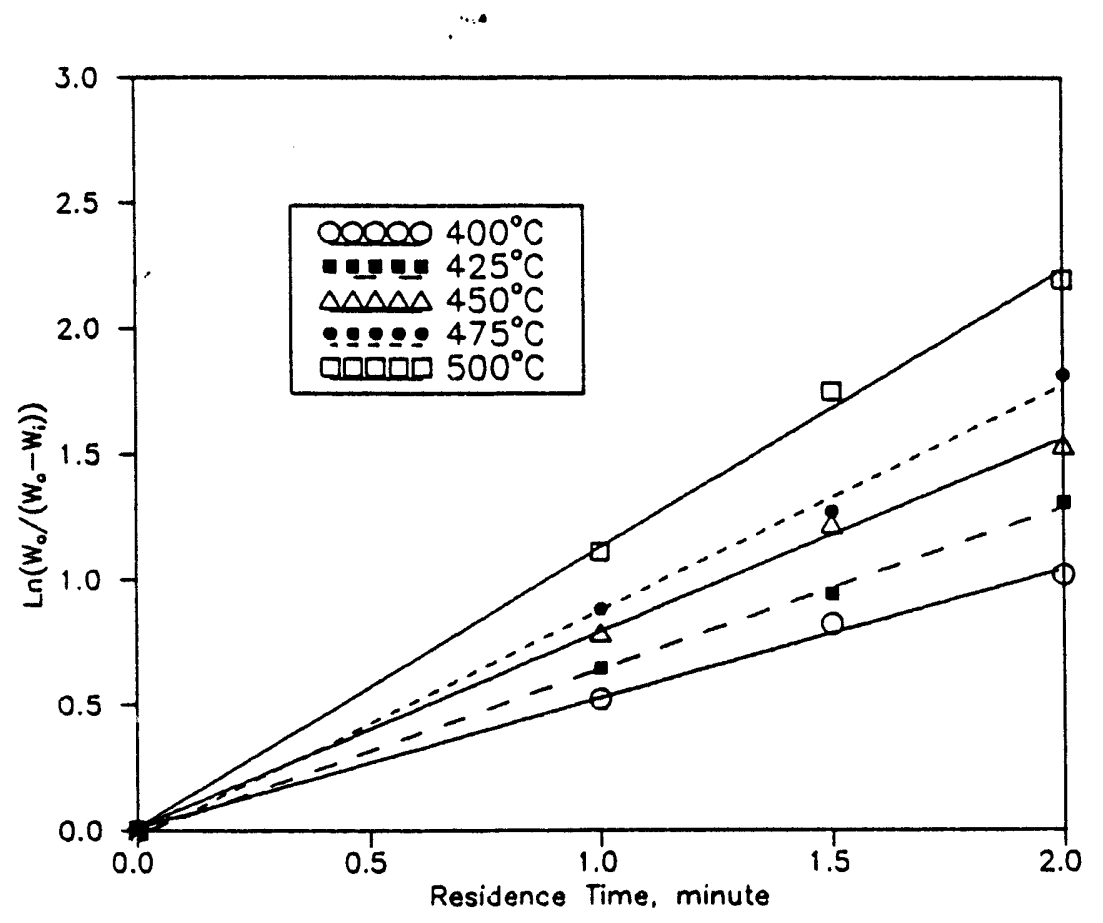

Figure 5.4.2(a) Devolatilization rate constant for the pyrolysis tests in the second phase

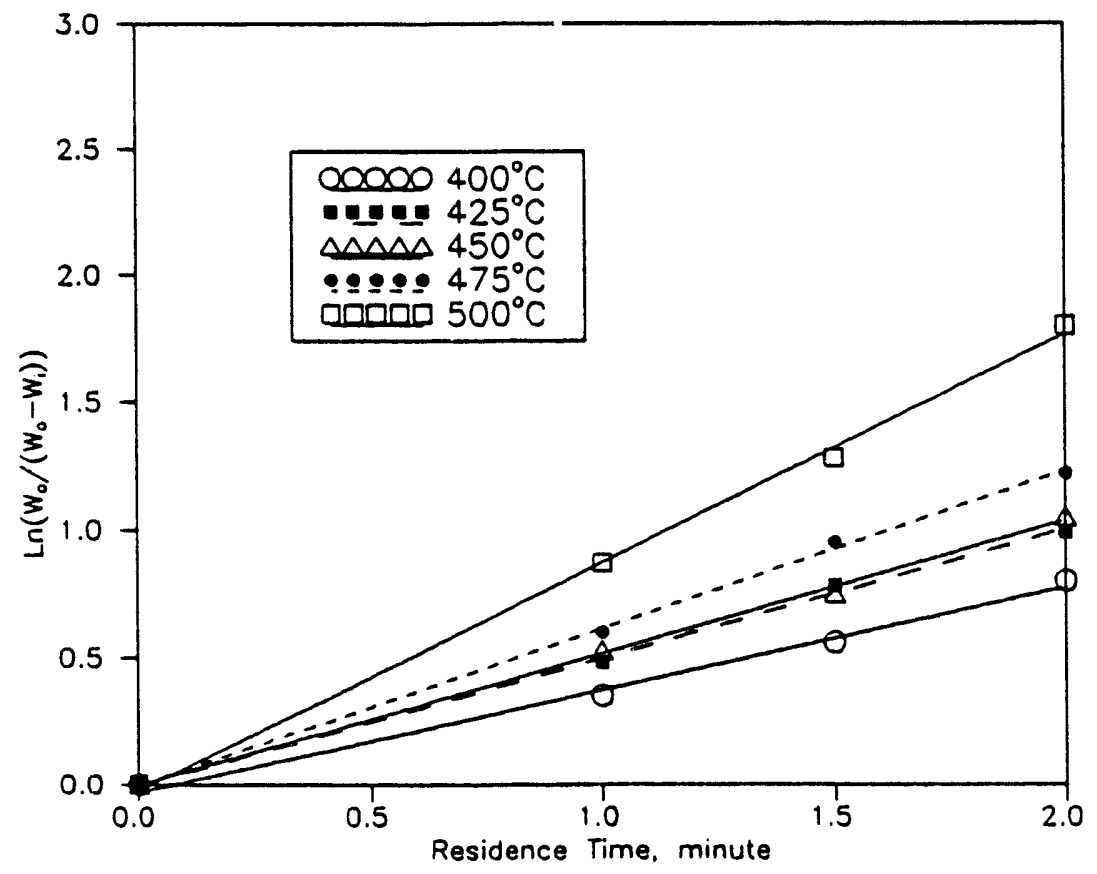

Figure 5.4.2(b) Denitrification rate constant for the pyrolysis tests in the second phase 


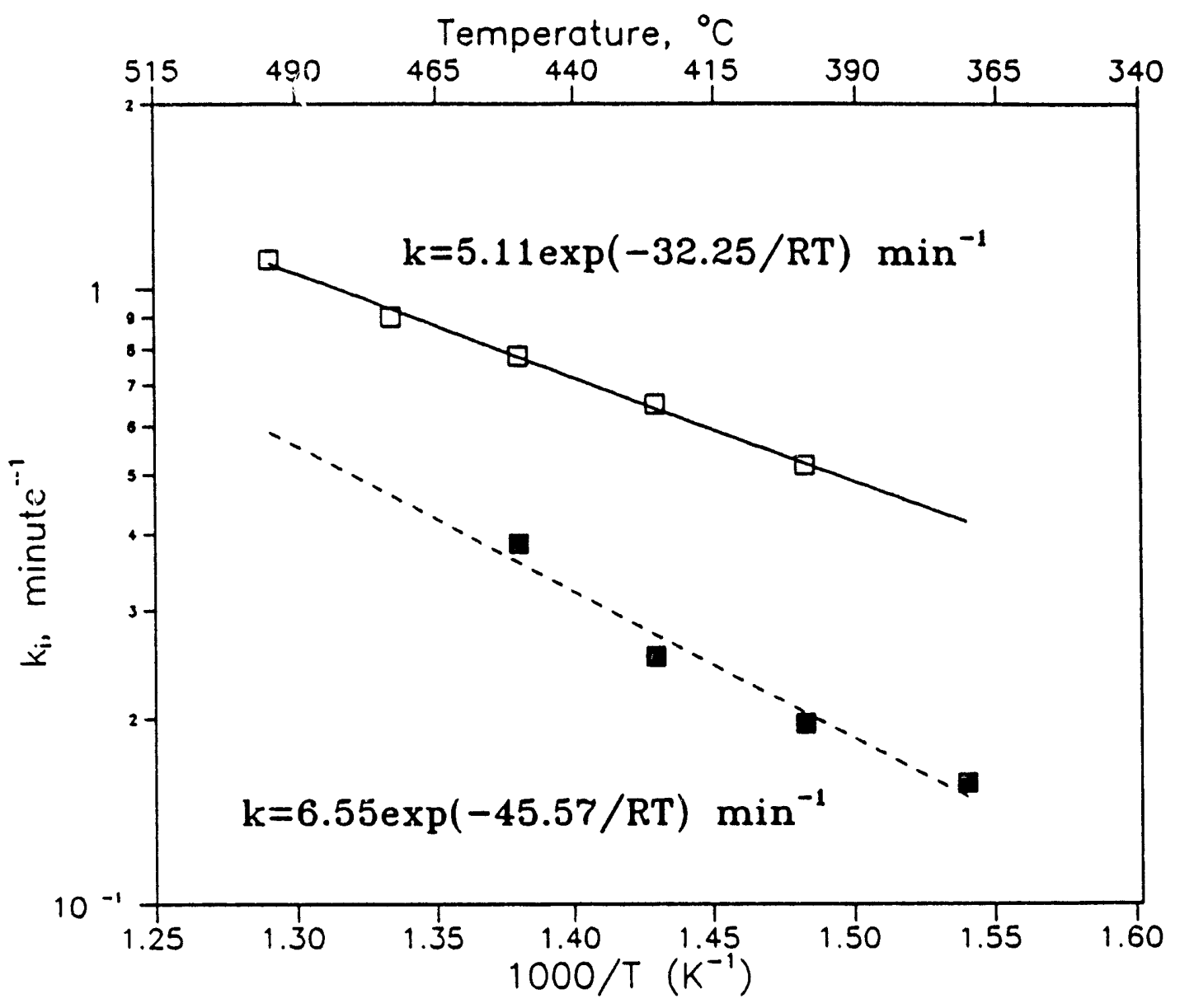

Figure 5.4.3 Arrhenius plot of devolatilization in the first ( $\square$ ) and second $(\square)$ phases tests

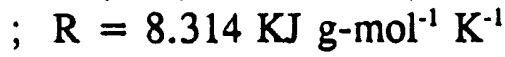




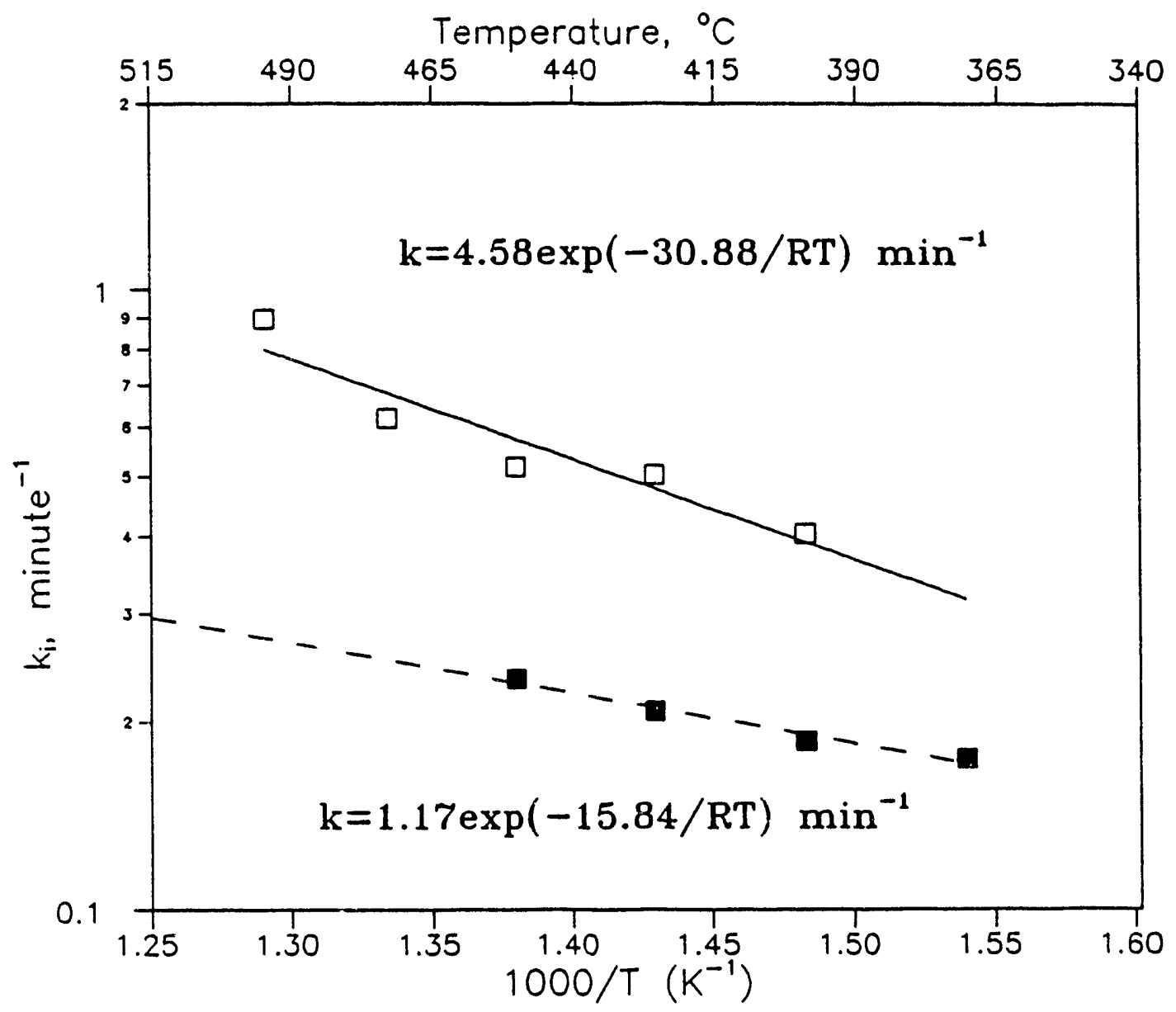

Figure 5.4.4 Arrhenius plot of denitrification in the first ( $\square$ ) and second $(\square)$ phases tests

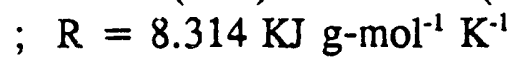




\section{CONCLUSIONS AND RECOMMENDATION}

The results of denitrification test of an Ohio No. 8 coal reported here demonstrate that an increasing the temperature in mild coal pyrolysis leads to an increase in the fraction of coal nitrogen converted to volatiles. The amount of nitrogen in the gas is calculated from a mass balance and indicates that a very small amount of gaseous nitrogen is evolved at a mild condition. Thus, all of the observations indicate that coal nitrogen is contained entirely in tightly bound rings which are released without breakage in the tar during mild pyrolysis of temperatures below $475^{\circ} \mathrm{C}$. The only coal nitrogen which can be removed is the volatile nitrogen. The fate of the volatile nitrogen in coal under mild pyrolysis is determined to a great extent by devolatilizatior.

The significance of fuel-nitrogen left behind in the char is the possibility of high conversion of coal nitrogen to NOx. A low conversion of fuel-nitrogen to NOx will be more favorable under mild pyrolysis condition with the subsequent burnout of the volatiles. A denitrification value of $17 \%$ was achieved at the temperature of $450^{\circ} \mathrm{C}$ in the first phase tests. It is believed that a higher value of denitrification could be accomplished at the temperatures higher than $475^{\circ} \mathrm{C}$ to some extent because the experimental results indicate that nitrogen evolution not only from primary volatilization but also from the secondary decomposition of tar.

An appreciable portion of the fuel-nitrogen results in the formation of intermediates as $\mathrm{HCN}$ and $\mathrm{NH}_{3}$ during flash pyrolysis at high temperature. Although there is no detectable amounts of both $\mathrm{HCN}$ and $\mathrm{NH}_{3}$, an improved sampling method is needed to identify ine gaseous nitrogen-containing species in the volatile.

The results of this research suggest that denitrification is very likely in high coal containing high amounts of volatiles. High rank coals have already been pyrolyzed at low temperatures during coalification with the resulting loss of functional groups with low bond energies.

On the other hand, the results of mass balance from the second phase testing suggest a negative pressure supply at the volatile sampling port will be in favored over releasing the volatile nitrogen from coal during pyrolysis. 


\section{REFERENCES}

1. Fine, D. H., Slater, S. M., Sarofim, A. F., and Williams, G. C., 'Nitrogen in coal as a source of nitrogen oxide emission from furnaces', Fuel, 53, 1974, p120

2. Fenimore, C. P., ' Reaction of fuel nitrogen in rich flame gases', Combustion and Flame, 26, 1976, p249

3. Morley, C., 'The formation and destruction of hydrogen cyanide from atmospheric and fuel-nitrogen in rich atmospheric-pressure flames', Combustion and Flame, 27, 1976, p189

4. Haynes, B. S., 'Reaction of ammonia and nitric oxide in the burnt gases of fuel rich hydrocarbon-air flames', Combustion and Flame, 28, 1977, p81

5. Altenkirch, R. A., Peck, R. E., and Chen, S. L., 'The appearance of nitric oxide and cyanide in one-dimensional coal dust/oxidizer flames', Combustion Science and Technology , 20, 1979, p49

6. Morley, C., 'The mechanism of nitric oxide formation from nitrogen compounds in hydrogen flames studies by laser fluorescence', 18th Symposium (International) on Combustion, The Combustion Institute, Pittsburgh, Penn., 1981, p23

7. Vogt, Robert A., and Laurendeau, Normand M., 'Effect of devolatilization on nitric oxide formation from coal nitrogen', Fuel, 57, 1978, p232

8. Levy, J. M., Pohl, J. H., Sarofim, A. F., Song, Y. H., 'Combustion research on the fate of fuel-nitrogen under conditions of pulverized coal combustion', US El'A/PB286208, 1978, p187

9. Levy, J. M., Longwell, J. P., Sarofim, A. F., 'NOx abatement in fossil fuel combustion - chemical kinetic considerations', Proceedings of the third Stationary Source Combustion Symposium, Vol. 4, 1979, US EPA/PB292542, p.3

10. Gorbaty, M. L., and Larsen, J. W., Wender, I. , Coal Science , Vol 1, Academic Press, New York, NY, 1982

11. Hauck, R. D., 'The genesis and stability of nitrogen in peat and coal', Prepr. , Division Fuel Chemistry, American Chemistry Society, 20, 2, 1975, p85

12. Albert, D. K., 'Determination of nitrogen compound types and distribution in petroleum by gas chromatography with a coulometric detector', Analytic 
Chemistry, 39, 1967, p1113

13. Snyder, L. R., 'Nitrogen and oxygen compound types in petroleum - total analysis of a $400 \sim 700^{\circ} \mathrm{F}$ distillate from a California crude oil', Analytic Chemistry, 41, 1969, p314

14. Meyers, Robert A., Coal Structure, Academic Press, New York, NY, 1982

15. Messenger, L., and Attar, A., 'Thermodynamics of the transformations of oxygen- and sulphur- containing functional groups during coal liquefaction in hydrogen and hydrogen donor', Fuel, 58, 1979, p655

16. Schiller, J. E., 'Nitrogen compounds in coal derived liquids', Analytic Chemistry, 49, 14, 1977, p2292

17. Leppälahti, J., and Kurkela, E., ' Behaviour of nitrogen compounds and tars in fluidized bed air gasification of peat', Fuel, 70, 1991, p491

18. Price, T. D., Smoot, L. D., and Hedman, P. O., ' Measurement of nitrogen and sulfur pollutants in an entrained-coal gasifier', Ind. Eng. Chem. Fundam., 22, 1983, p110

19. Nichols, K. M., Hedman, P. and Smoot, L. D., 'Release and reaction of fuelnitrogen in a high-pressure entrained coal gasifier', Fuel, 66, 1987, p1257

20. Anthony, D. B., and Howard, J. B., ' Coal devolatilization and hydrogasification', AlChE J., 22, 1976, p625

21. Howard J. B., ' Fundamentals of coal pyrolysis and hydropyrolysis ', Chemistry of Coal Utilization, Second Supplementary Volume(Elliot, M. A.), Wiley, New York, 1981, Chapter 12.

22. Howard, J. B., Peters, W. A., and Serio, M. A., Coal Devolatilization Information for Reactor Modeling, Final Report, EPRI Project No. 986-5, 1981

23. Solomon, P. R., and Colket, M. B., 'Evolution of fuel nitrogen in coal devolatilization', Fuel, 57, 1978, p748

24. Solomon, P. R., and Colket, M. B., 'Coal devolatilization', 17th Symposium (International) on Combustion, The Combustion Institute, Pittsburgh, Penn., 1979, p131

25. Solomon, P. R., 'Relation between coal aromatic carbon concentration and proximate analysis fixed carbon', Fuel, 60, 1981, p3 
26. Solomon, P. R., Hobbs, R. H., Hamblen, D. G., Chen, W. Y., La Cava, A. and Graff, R. S., 'Correlation of coal volatile yield with oxygen and aliphatic hydrogen', Fuel, 60, 1981, p342

27. Solomon, P. R., Hamblen, D. G., Carangelo R. M., and Krause, J. L., 'Coal thermal decomposition in an entrained flow reactor : experiments and theory', 19th Symposium (International) on Combustion, The Combustion Institute, Pittsburgh, Penn., 1981, p1139

28. Gray, D., ' Inherent mineral matter in coal and its effect upon hydrogenation', Fuel, 57, 1978, p213

29. Johnson, J. L., Prepr. , Division Fuel Chemistry, American Chemistry Society, 20, 4, 1975, p85

30. Fuller, E. L., ' Annual Report of ORNL Chemistry Division for 1978', ORNL5485, Oak Ridge National Lab., Oak Ridge, Tenn., 1979, p13

31. Rahman, M., , and Vahrman, M., 'The smaller molecules obtainable from coal and their significance : Part 2 - High pressure extraction at $200-300^{\circ} \mathrm{C}$ ', Fuel , 50, 1971, p318

32. Palmer, T., J., and Vahrman, M, 'The smaller molecules obtainable from coal and their significance : Part 3 - Steaming/carbonization of a weakly caking coal at temperatures up to $600^{\circ} \mathrm{C}^{\prime}$, Fuel $, 51,1972$, p 14

33. Palmer, T. J., and Vahrman, M, 'The smaller molecules obtainable from coal and their significance : Part 4 - Composition of low-temperature tar', Fuel, 51, 1972, p22

34. Watts, R. H., and Vahrman, M, 'The smaller molecules obtainable from coal and their significance : Part 5 - Composition of vacuum tar', Fuel, 51, 1972, p130

35. Watts, R. H., and Vahrman, M, 'The smaller molecules obtainable from coal and their significance : Part 6 - hydrocarbons from coal heated in their layers', Fuel , 51, 1972, p235,

36. Hayatsu, R., Winans, R. W., Scott, R. G., Moore, L. P., and Studier, M. H., 'Trapped organic compounds and aromatic units in coals' Fuel , 57, 1977, p541

37. Suuberg, E. M., Lee, D. and Larsen, J. W., 'Temperature dependence of crosslinking processes in pyrolysing coals' Fuel, 64, 1985, p1668

38. Fitzgerald, D., and van Krevelen, D. W., 'The kinetics of coal carbonization', 
Fuel, 38, 1959, p17

39. Howard, J. B., Peters, W. A., and Serio, M. A., Coal Devolatilization Information for Reactor Modeling, Final Report, EPRI Project No.986-5, 1981

40. 1989 Annual Book of ASTM Standards, section 5, vol 05.05, Philadelphia, Penn.

41. Standard Methods for the Examination of water and wastewater, 17th ed., American Public Health Association, Washington, D.C., 1989 

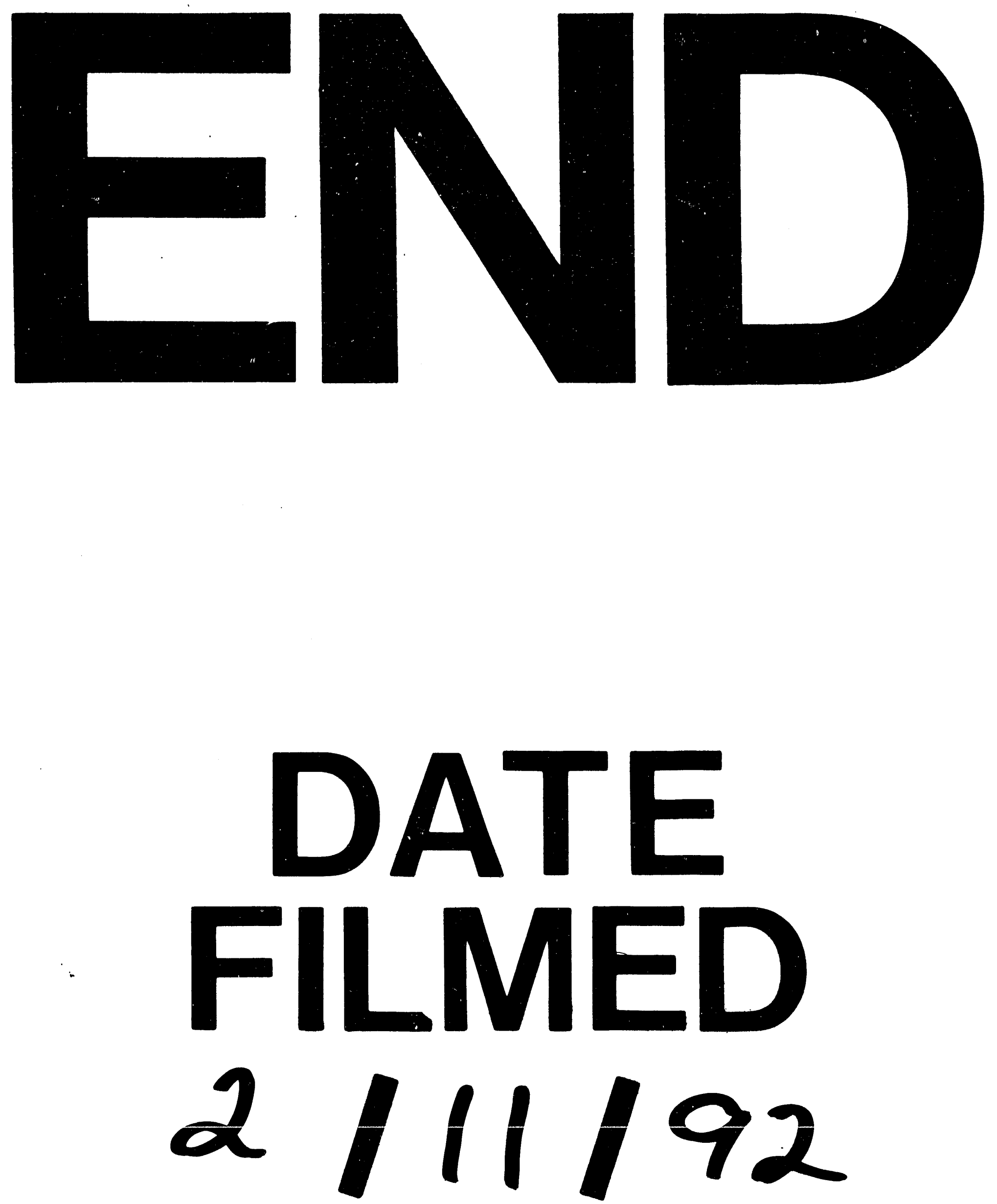
